\title{
1 Performance testing of a cross-flow membrane-based liquid desiccant
}

2 dehumidification system

Hongyu Bai ${ }^{\mathrm{a}}$, Jie Zhu ${ }^{\mathrm{a}, *}$, Ziwei Chen ${ }^{\mathrm{a}}$, Lina Ma ${ }^{\mathrm{a}}$, Ruzhu Wang ${ }^{\mathrm{b}}$, Tingxian $\mathrm{Li}^{\mathrm{b}}$

${ }^{a}$ Department of Architecture and Built Environment, the University of Nottingham, University

Park, Nottingham, NG7 2RD, UK

${ }^{b}$ Institute of Refrigeration and Cryogenics, Key Laboratory for Power Machinery and

8 Engineering of M.O.E, Dongchuan Rd. 800\#, Shanghai Jiao Tong University, Shanghai,

200240, China

\section{Abstract}

A membrane-based liquid desiccant dehumidification system is one of high energy efficient dehumidification approaches, which allows heat and moisture transfers between air stream and desiccant solution without carryover problem. The system performance is investigated experimentally with calcium chloride, and the impacts of main operating parameters on dehumidification effectiveness (i.e. sensible, latent and total effectiveness) are evaluated, which include dimensionless parameters (i.e. solution to air mass flow rate ratio $\mathrm{m}^{*}$ and number of heat transfer units $N T U$ ) and solution properties (i.e. concentration $C_{s o l}$ and inlet temperature $\left.T_{\text {sol,in }}\right)$. The sensible, latent and total effectiveness reach the maximum values of $0.49,0.55$, and 0.53 respectively at $m^{*}=3.5$ and $N T U=12$, and these effectiveness are not limited by $m^{*}$ and $N T U$ when $m^{*}>2$ and $N T U>10$. Both the latent and total effectiveness increase with $C_{s o l}$, while almost no variation is observed in the sensible effectiveness. All effectiveness can be improved by decreasing $T_{\text {sol,in }}$. The experimental data provide a full map of main design parameters for the membrane-based liquid desiccant air conditioning technology.

Keywords: liquid desiccant, membrane-based, dehumidification, performance testing, effectiveness 


$\begin{array}{ll}A & \text { membrane surface area }\left(\mathrm{m}^{2}\right) \\ A H & \text { absolute humidity }\left(\mathrm{kg} / \mathrm{m}^{3}\right) \\ c_{p} & \text { specific heat capacity }(\mathrm{J} / \mathrm{kgK}) \\ C & \text { concentration }(\%) \\ C_{r}{ }^{*} & \text { capacitance ratio } \\ d & \text { width of the rectangular channel }(\mathrm{m}) \\ h & \text { convective heat transfer coefficient }\left(\mathrm{W} / \mathrm{m}^{2} \mathrm{~K}\right) \\ H & \text { height of the rectangular channel }(\mathrm{m}) \\ H^{*} & \text { operating factor } \\ k & \text { thermal conductivity }(\mathrm{W} / \mathrm{m} \mathrm{K}) \\ L & \text { characteristic length of the rectangular channel }(\mathrm{m}) \\ m^{*} & \text { solution to air mass flow rate ratio } \\ \dot{m} & \text { mass flow rate }(\mathrm{kg} / \mathrm{s}) \\ N u & \text { Nusselt number } \\ N T U & \text { number of heat transfer units } \\ N T U_{m} & \text { number of mass transfer units } \\ P & \text { atmospheric pressure }(\mathrm{pa}) \\ P_{v} & \text { equilibrium vapour pressure of desiccant solution }(\mathrm{pa}) \\ R H & \text { relative humidity }(\%) \\ T & \text { temperature }\left({ }^{\circ} \mathrm{C}\right) \\ U & \text { overall heat transfer coefficient }\left(\mathrm{W} / \mathrm{m}^{2} \mathrm{~K}\right) \\ H^{*} & \text { volumetric flow rate }(\mathrm{l} / \mathrm{min}) \\ & \end{array}$

\section{Greeks}

$\varepsilon$

effectiveness

$\delta \quad$ thickness of membrane (m)

$\rho \quad$ density $\left(\mathrm{kg} / \mathrm{m}^{3}\right)$

\section{Subscripts}

air air flow

crit critical value

in inlet

lat latent 


$\begin{array}{ll}\text { mem } & \text { membrane } \\ \text { min } & \text { minimum value } \\ \text { out } & \text { outlet } \\ \text { sen } & \text { sensible } \\ \text { sol } & \text { solution flow } \\ \text { tol } & \text { total }\end{array}$

\section{Introduction}

Buildings consume a significant part of the global total energy, particularly heating, ventilation and air-conditioning (HVAC) systems are responsible for around 50\% of the energy consumed in buildings [1]. As a matter of fact, the energy consumption for dehumidification process accounts for $20-40 \%$ of the total energy used in HVAC systems, and it can be higher when $100 \%$ fresh air ventilation is required for better indoor environment [2]. Without proper air dehumidification, occupants would feel uncomfortable and mildew would grow on building interior walls in the humid region. Furthermore, production safety and quality would be seriously affected by high humidity level [2]. It has been shown that the building energy consumption could be decreased by $20-64 \%$ with efficient dehumidification technologies [3]. Currently, cooling coil is mostly preferred for dehumidification [4], which adopts cooled water as the cold medium generated from vapour compression system (VCS). The conventional VCS has advantages of good stability in performance, long life and a reasonable electrical COP (between 2 and 4) [5]. However, the working fluids used in VCS such as R-22, R-410A and R134A with the high global warming potential are harmful to the environment. Furthermore, VCS consumes substantial amount of electrical energy [6]. In the traditional cooling coil, air dehumidification is undertaken simply by cooling air below its dew point for condensation in order to reduce its moisture content. Normally, this type of dehumidification is followed by reheating the dehumidified air to a desired temperature. Consequently, this combined process consumes a considerable amount of energy to cool (typically using a VCS) and heat (using hot water or electricity) the supply air [7].

60 In the traditional desiccant system, the vapour pressure gradient between humid air and 61 desiccant results in heat and moisture transfers [8,9]. The system operates using either solid or 62 liquid desiccant. Solid desiccant system is compact, simple and less subject to desiccant carryover and corrosion problems, while liquid desiccant system has lower regeneration 64 temperature, higher dehumidification capacity and lower air side pressure drop [10]. Liquid 65 desiccants can be regenerated using low-grade heat sources such as solar energy, and the 66 regenerated solution can be used as energy storage medium as well [11]. In such way, the liquid desiccant system has been well developed recently. 
The traditional liquid desiccant system commonly adopts the packed bed, where air and desiccant are in direct contact. Comprehensive researches have been conducted on the direct contact system [12-15], and it has been found that air conditioning energy consumption reduces by up to $26-80 \%$ in the hot and humid climate. However, in the direct contact system, small desiccant droplets are carried over by the supply air to the indoor environment, which badly affects the occupant health, building structure and furniture [2].

Recently, selectively permeable membrane has been used to replace the packed bed as the heat and mass transfer medium to overcome the desiccant droplet carryover problem. Semipermeable membrane is able to prevent the solution from carrying over into the supply air, while selectively permitting heat and moisture transfers between the liquid desiccant and supply air $[2,16-20]$. The selectively permeable membrane can be classified into two types: parallel plate [21-33] and hollow fiber [34-38]. Several researches have been carried out to investigate the membrane-based dehumidifier performance. For example, Moghaddam et al. [21] experimentally and numerically studied different parameter influences on the steady state performance of a small-scale counter-flow liquid-to-air membrane energy exchanger (LAMEE), these parameters include thermal capacity ratio $\left(\mathrm{Cr}^{*}\right)$, number of heat transfer units $(N T U)$ and number of mass transfer units $\left(N T U_{m}\right)$. Hemingson et al. [22, 23] developed a model of moisture transfer resistance between the membrane and solution for a counter-flow LAMEE, and conducted experimental tests under a range of outdoor weather conditions. Fan et al. [24, 25] built a mathematical model for a single cross-flow LAMEE, which is applied to a runaround LAMEE system consisting of both dehumidifier and regenerator. The impacts of $\mathrm{Cr}^{*}$, $N T U$ and $N T U_{m}$ on both sensible and latent effectiveness of the run-around system are evaluated. Seyed-Ahmadi et al. [26, 27] developed a mathematical model to simulate the transient behaviours of a single cross-flow LAMEE and a run-around LAMEE, which is also compared with Fan's steady state model. Apart from counter and cross flows, an innovative flow configuration, counter-cross flow, has been investigated. Vali et al. [28, 29] modelled a run-around LAMEE system using the counter-cross flow exchangers as dehumidifier and regenerator, and assessed the steady state system performance. Moghaddam et al. [30] studied the effect of the direction of heat and mass transfer inside the counter-cross flow LAMEE through experiment and numerical simulation. However, in the above researches, the fundamental data required for mathematical modelling such as Nusselt number $(\mathrm{Nu})$ and Sherwood number $(S h)$ are simply borrowed from well-known books, which are generally obtained under uniform temperature or heat flux boundary condition. Thus they are unable to reflect the real heat and mass transfer properties. To solve this problem, Huang et al. [31] proposed a mathematical model for the cross-flow parallel-plate membrane module to conjugate heat and mass transfer in a cross-flow LAMEE under a fully developed flow 
104 condition. The fundamental data of $N u$ and $S h$ under various aspect ratios are calculated.

105 However, the assumption of a fully developed flow is not reasonable in this model. Accordingly, 106 they [32] improved this model by considering the effect of the developing entrance length on 107 the fluid flow pattern.

108 Most of the researches in literatures focus on numerical modelling of heat and mass transfer in 109 LAMEE. Some of them experimentally assess the LAMEE performance for different heat and 110 mass transfer directions or liquid desiccant types [3] [30]. Some researchers analyse the impacts 111 of $N T U$, solution to air mass flow rate ratio $\left(m^{*}\right)$, and solution inlet temperature $\left(T_{\text {sol,in }}\right)$ on 112 whole liquid desiccant air-conditioning system [39]. A few studies investigate the membrane113 based dehumidifier performance with regard to $N T U, m^{*}$ and solution inlet concentration $\left(C_{s o l}\right)$ 114 [21-25][40]. Thus in order to get a full map of the operating characteristics of a LAMEE, a 115 series of experimental tests are carried out in this study to evaluate the performance of a full116 scale membrane-based cross-flow liquid desiccant dehumidifier. The experimental results are 117 presented with regard to the four important operating parameters: $N T U, m^{*}, T_{\text {sol,in }}$ and $C_{\text {sol }}$. 118 This work provides a comprehensive parametric study on the dehumidifier performance 119 through experimental investigations, which supplies valuable data for liquid desiccant air 120 conditioning system design.

\section{Test Apparatus and Instrumentation}

123 A test facility is designed and built in the laboratory to assess the performance of a cross-flow 124 membraned-based liquid desiccant dehumidification system under different operating conditions. The test rig mainly consists of a dehumidifier, a regenerator, two solution tanks and three heat exchange units. The schematic diagram of the test rig is shown in Fig. 1, and the dehumidifier specifications and membrane physical properties are given in Table 1.

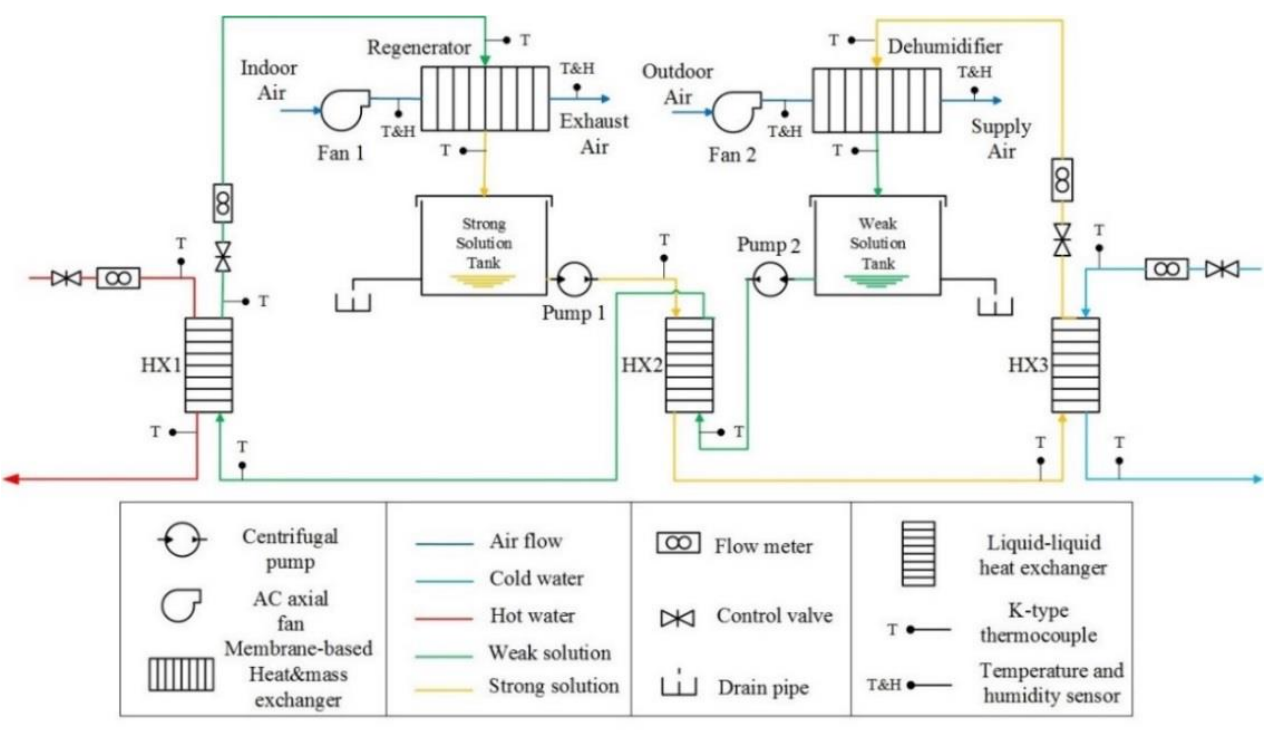

Fig. 1. Schematic diagram of the laboratory test rig 
131 Dehumidifier specifications and membrane physical properties

\begin{tabular}{|c|c|c|}
\hline Symbol & Unit & Value \\
\hline$L^{*}$ & $m$ & 0.23 \\
\hline$W^{*}$ & $m$ & 0.41 \\
\hline$H$ & $m$ & 0.21 \\
\hline$d_{\text {air }}$ & $m$ & 0.0077 \\
\hline$d_{\text {sol }}$ & $m$ & 0.0043 \\
\hline$\delta_{\text {mem }}$ & $m$ & $1.05 \times 10^{-4}$ \\
\hline$k_{\text {mem }}$ & $W / m K$ & 0.3 \\
\hline
\end{tabular}

132

133

134

135

136

\subsection{Air loop}

The outdoor air flows into the dehumidifier where both its moisture content and temperature are reduced by cold desiccant solution, then it leaves the dehumidifier unit at dry and cool state. Its flow rate is controlled by adjusting an $\mathrm{AC}$ axial fan rotation speed (ebm-papst Mulfingen $\mathrm{GmbH} \& \mathrm{Co} . \mathrm{KG})$. An air conditioning unit and a humidifier are used to simulate the hot and humid weather condition. The dehumidifier structure is illustrated in Fig. 2. The dehumidifier has a dimension of $410 \mathrm{~mm}(\mathrm{~L})$ x 230mm (W) x 210mm (H) with 11 air channels and 11 solution channels. As can be seen in Fig. 2, wavy polyethylene sheets are used to support the air channels. Air and desiccant solution flows are in a cross configuration. Heat and mass transfer takes place in semi-permeable membranes that separate the air and solution channels. Three gauze layers are paved on the top surface of the dehumidifier unit to ensure even solution distribution.

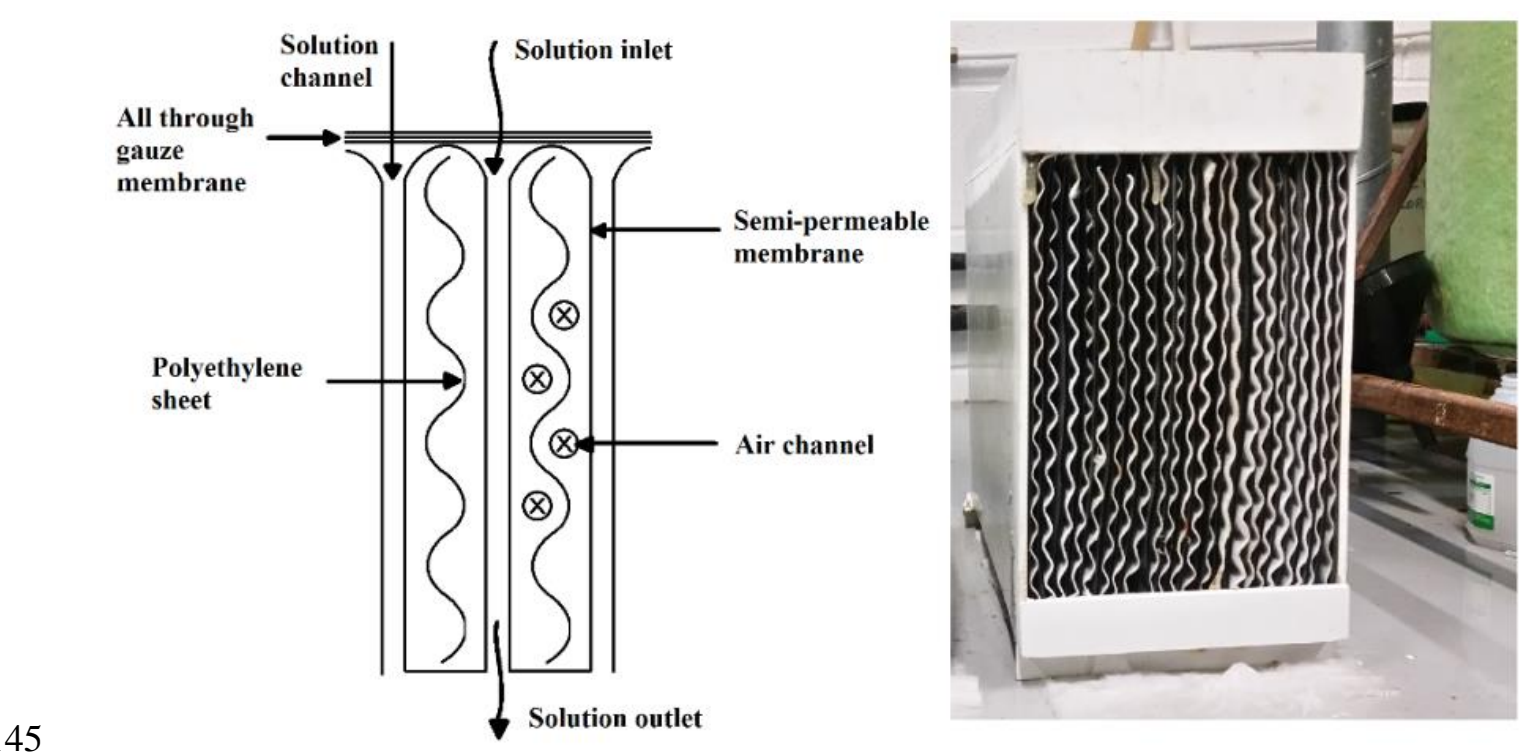

Fig. 2. Schematic diagram of the dehumidifier 
150

\subsection{Liquid loop}

151 Calcium chloride $\left(\mathrm{CaCl}_{2}\right)$ solution is circulated in the system by two identical pumps $(15 \mathrm{~W}$

152 centrifugal magnetically driven type with flow rate range of $0-10 \mathrm{~L} / \mathrm{min}$ ) and their flow rates are

153 measured by two liquid flow indicators (Parker UCC PET 1-15 L/min). Before entering the

154 dehumidifier, the strong solution is pre-cooled in a brazed plate heat exchanger HX2 by the

155 weak solution, and further cooled in HX3 by cold water. Afterwards, the strong solution is

156 pumped into the dehumidifier and sprayed through a nozzle. Then the strong solution flows

157 downwards in the solution channels, absorbs the moisture from the air and becomes weak

158 solution. The weak solution is then pumped into HX2 for pre-heating, followed by further-

159 heating in HX1 by hot water. The heated weak solution is pumped into the regenerator. The re-

160 concentrated solution from the regenerator is collected by a stainless steel solution tank. Then

161 the strong solution is pumped out of the strong solution tank to HX2 and a whole circuit is

162 completed. The desiccant solution and air transport properties are listed in Table 2.

163 Table 2

164 Air and desiccant solution transport properties

\begin{tabular}{|c|c|c|}
\hline Symbol & Unit & Value \\
\hline$k_{\text {air }}$ & $W / \mathrm{mK}$ & 0.03 \\
\hline$k_{\text {sol }}$ & $W / \mathrm{mK}$ & 0.5 \\
\hline$D_{\text {air }}$ & $\mathrm{m}^{2} / \mathrm{s}$ & $2.46 \times 10^{-5}$ \\
\hline$D_{\text {sol }}$ & $\mathrm{m}^{2} / \mathrm{s}$ & $0.892 \times 10^{-2}$ \\
\hline$c_{p, \text { air }}$ & $\mathrm{J} / \mathrm{kgK}$ & 1020 \\
\hline$c_{p, \text { sol }}$ & $\mathrm{J} / \mathrm{kgK}$ & 3200 \\
\hline$\rho_{\text {air }}$ & $\mathrm{kg} / \mathrm{m}^{3}$ & 1.29 \\
\hline
\end{tabular}

165

166

167

168

169

170

171

172

173

174

175

176

177

178

\subsection{Instrumentation}

Air velocities through the dehumidifier and regenerator are measured at the air duct outlets by a thermo-anemometer (Testo 405) with a measuring range up to $10 \mathrm{~m} / \mathrm{s}$. All fans at the inlets of the dehumidifier and regenerator are equipped with infinitely variable speed controllers to adjust air flow rates. All air inlets and outlets are instrumented with humidity and temperature sensors (Sensirion Evaluation KIT EK-H4). Water and desiccant solution temperatures are measured with K-type thermocouples, and all sensors are connected to a DT500 data logger. The dehumidifier, regenerator, heat exchangers, storage tanks and pipes are well insulated to reduce the environment influence.

A correlation based on Melinder's work [41] is used to determine the solution concentration, which is a function of solution density and temperature. The correlation is given as:

$$
C_{\text {sol }}=-253.147703+0.0443853996 T_{\text {sol }}+0.000163666247 T_{\text {sol }}^{2}
$$

$$
+0.331709855 \rho_{\text {sol }}-0.000079370267 \rho_{\text {sol }}^{2}
$$


179 Where $C_{\text {sol }}$ is solution concentration (\%). $T_{\text {sol }}$ is solution temperature $\left({ }^{\circ} \mathrm{C}\right)$ and $\rho_{\text {sol }}$ is solution 180 density $(\mathrm{g} / \mathrm{ml})$. The solution density is measured by Brannan hydrometers. All measurement 181 devices and their accuracies are listed in Table 3

182 Table 3

183 Measurement devices and uncertainties

\begin{tabular}{|l|l|l|l|}
\hline Device & Measurement & Range & Uncertainty \\
\hline Testo thermos-anemometer & Air velocity & $0-10 \mathrm{~m} / \mathrm{s}$ & $\pm 5 \%$ \\
\hline Sensiron Evaluation KIT EK-H4 & Temperature & $-40-125^{\circ} \mathrm{C}$ & $\pm 0.4 \%$ \\
& Relative humidity & $0-100 \%$ & $\pm 3 \%$ \\
\hline K-type thermocouple probe & Temperature & $0-1100{ }^{\circ} \mathrm{C}$ & $\pm 0.75 \%$ \\
\hline DT500 Datalogger & Data acquisition & - & $\pm 0.15 \%$ \\
\hline Parker UCC PET liquid flow indicator & Solution flow rate & $1-15 \mathrm{~L} / \mathrm{min}$ & $\pm 5 \%$ \\
\hline Parker liquid flow indicator & Water flow rate & $2-22 \mathrm{~L} / \mathrm{min}$ & $\pm 2 \%$ \\
\hline Brannan hydrometer & Density & $1-1.2 \mathrm{~g} / \mathrm{ml}$ & $\pm 2 \%$ \\
\hline Brannan hydrometer & Density & $1.2-1.4 \mathrm{~g} / \mathrm{ml}$ & $\pm 2 \%$ \\
\hline
\end{tabular}

\subsection{Uncertainty analysis}

186 Uncertainty analysis provides a measure of the errors during a measurement associated with a 187 calculated value. Thus it is of vital importance to estimate uncertainties during the experiment.

188 Based on a method of propagation of uncertainties introduced by Taylor [42], when the 189 computed value $q$ is any function of several variables $x, \cdots, z$, the uncertainty of $q$ can be 190 obtained by:

192 Based on Eq. (2), the absolute uncertainty of a calculated value can be derived. Error bars are

193 included in the graphs for experimental result analyses. The detail uncertainties for all target 194 measurements are given in Appendix.

\section{Experimental methodology}

197 The system performance indicators and relevant parameters are defined in this section, and the

198 experimental procedures for dimensionless parameter and solution property tests are presented.

\subsection{Dehumidifier performance evaluation}

\subsubsection{Operating parameters}

\subsubsection{Capacitance ratio $\left(C_{r}{ }^{*}\right)$}

202 Heat capacity rate is defined as the product of specific heat capacity and mass flow rate $(W / K)$.

203 Thus the heat capacities of desiccant solution and air are expressed by Eqs. (3)-(4) [43].

$204 \quad C_{s o l}=\dot{m}_{s o l} c_{p, s o l}$ 
Where $\dot{m}_{s o l}$ is solution mass flow rate $(\mathrm{kg} / \mathrm{s}), \dot{m}_{\text {air }}$ is air mass flow rate $(\mathrm{kg} / \mathrm{s}), c_{p, s o l}$ is solution specific heat capacity $(J / k g K)$ and $c_{p, a i r}$ is air specific heat capacity $(J / k g K)$.

Then the capacitance ratio (or heat capacity rate ratio) $C_{r}{ }^{*}$ is given by Eq. (5) [11].

$C_{r}^{*}=\frac{C_{\text {sol }}}{C_{\text {air }}}=\frac{\dot{m}_{s o l} c_{p, \text { sol }}}{\dot{m}_{\text {air }} c_{p, \text { air }}}$

\subsubsection{Solution to air mass flow rate ratio $\left(m^{*}\right)$}

211 Solution to air mass flow rate ratio is a measurement of relative flow rate of two heat exchanging fluids. In this experiment, the solution to air mass flow rate ratio $\left(m^{*}\right)$ is used since it is a more straight forward parameter. The solution to air flow rate ratio is defined as:

$214 \quad m^{*}=\frac{\dot{m}_{\text {sol }}}{\dot{m}_{\text {air }}}$

\subsubsection{Operating factor $\left(H^{*}\right)$}

Operating factor is a dimensionless number defined as the ratio between the latent energy difference and sensible energy difference for the air and desiccant solution at the inlets [29].

$218 H^{*}=\frac{\Delta H_{\text {lat }}}{\Delta H_{\text {sen }}} \approx 2500 \frac{W_{\text {air, in }}-W_{\text {sol,in }}}{T_{\text {air, in }}-T_{\text {sol, in }}}$

Where $T_{\text {air,in }}$ and $T_{\text {sol,in }}$ are air and solution temperatures respectively $\left({ }^{\circ} \mathrm{C}\right), W_{\text {air, in }}$ is air humidity ratio $(\mathrm{kg} / \mathrm{kg})$ and $W_{\text {sol,in }}$ is solution equilibrium humidity ratio $(\mathrm{kg} / \mathrm{kg})$.

3.1.1.4 Number of heat transfer units (NTU)

Effectiveness-NTU method is one of the most commonly used ways for heat exchanger analysis. Compared with log-mean-temperature-difference method, it provides a superior way to analyse heat exchanger in terms of non-dimensional variables [44].

$225 \quad N T U=\frac{U A}{C_{\min }}$

$U=\left[\frac{1}{h_{\text {air }}}+\frac{\delta}{k_{\text {mem }}}+\frac{1}{h_{\text {sol }}}\right]^{-1}$

227 Where $U$ is the overall heat transfer coefficient $\left(W / m^{2} K\right), A$ is membrane surface area $\left(m^{2}\right)$,

$228 C_{\min }$ is the minimum value of air and desiccant solution heat capacity rates $(W / K), h_{\text {air }}$ is air

229 convective heat transfer coefficient $\left(W / m^{2} K\right), h_{s o l}$ is solution convective heat transfer

230 coefficient $\left(W / m^{2} K\right), \delta$ is membrane thickness $(m)$ and $k_{m e m}$ is membrane thermal 231 conductivity $(W / m K)$.

232 3.1.1.5 Number of mass transfer units $\left(N T U_{m}\right)$

233 The number of mass transfer units is defined as following:

$234 N T U_{m}=\frac{U_{m} A}{\dot{m}_{\min }}$

$U_{m}=\left[\frac{1}{h_{m, a i r}}+\frac{\delta}{k_{m}}+\frac{1}{h_{m, s o l}}\right]^{-1}$ 
Where $U_{m}$ is the overall mass transfer coefficient $\left(\mathrm{kg} / \mathrm{m}^{2} \mathrm{~s}\right), \dot{m}_{\min }$ is the minimum mass flow rate of air and desiccant solution $(\mathrm{kg} / \mathrm{s}), h_{m \text {,air }}$ is convective mass transfer coefficient of air $\left(\mathrm{kg} / \mathrm{m}^{2} \mathrm{~s}\right), h_{m, s o l}$ is convective mass transfer coefficient of desiccant solution $\left(\mathrm{kg} / \mathrm{m}^{2} \mathrm{~s}\right), \delta$ is thickness of membrane $(\mathrm{m}), k_{m}$ is membrane water permeability $(\mathrm{kg} / \mathrm{ms})$. It has been showed the convective mass transfer coefficient of desiccant solution is much higher than that of the air, thus $\frac{1}{h_{m, s o l}}$ can be neglected for the simplicity.

\subsubsection{Effectiveness}

243 Effectiveness is the most important parameter used to evaluate the performance of a heat and 244 mass exchanger [45]. Three types of effectiveness have been defined in this study: sensible 245 effectiveness $\left(\varepsilon_{\text {sen }}\right)$, latent effectiveness $\left(\varepsilon_{\text {lat }}\right)$ and total effectiveness $\left(\varepsilon_{\text {tot }}\right) \cdot \varepsilon_{\text {sen }}$ is the ratio 246 between the actual and maximum possible rates of sensible heat transfer in a heat exchanger.

$247 \varepsilon_{\text {lat }}$ is the ratio between the actual and the maximum possible moisture transfer rates in a mass 248 exchanger. $\varepsilon_{\text {tot }}$ is the ratio between the actual and maximum possible energy (enthalpy) 249 transfer rates in a heat and mass exchanger. The capacity rate of desiccant solution is higher 250 than that of the air, which means $C r^{*} \geq 1$, then the sensible, latent and total effectiveness are 251 defined by Eqs. (12) - (14). [46].

$\varepsilon_{\text {lat }}=\frac{W_{\text {air }, \text { in }}-W_{\text {air }, \text { out }}}{W_{\text {air, in }}-W_{\text {sol,in }}}$

$\varepsilon_{\text {tol }}=\frac{\varepsilon_{\text {sen }}+H^{*} \varepsilon_{\text {lat }}}{1+H^{*}}$

Where $T_{\text {air,out }}$ is air temperature at the outlet $\left({ }^{\circ} \mathrm{C}\right)$ and $W_{\text {air,out }}$ is air humidity ratio at the outlet $(\mathrm{kg} / \mathrm{kg})$.

\subsection{Experimental procedure}

\subsubsection{Dimensionless parameter tests}

260 At first, the experiment aims to explore the impacts of number of heat transfer units $(N T U)$ and solution to air mass flow rate ratio $\left(\mathrm{m}^{*}\right)$ on the dehumidifier performance. The air inlet condition is set at a temperature of $30^{\circ} \mathrm{C}$ and relative humidity (RH) of $70 \%$, and the solution concentration is $39 \%$. NTU is set in the range of 4 to 12 . For each $N T U$, seven tests are conducted with $m^{*}$ set as $0.5,1,1.5,2,2.5,3$ and 3.5. Because air heat capacity rate is always lower than desiccant solution's, thus Eq. (8) can be written as:

$$
N T U=\frac{U A}{c_{p, a i r} \dot{m}_{\text {air }}}
$$

In order to determine the required air mass flow rate for a corresponding $N T U$, the overall heat transfer coefficient ( $U$ value) needs to be decided at first. According to Eq. (9), $\delta$ and $k_{m e m}$ are physical properties of the membrane material, so $h_{\text {air }}$ and $h_{\text {sol }}$ need to be determined. In this 
experiment, these two parameters are obtained from air side Nusselt number $\left(N u_{\text {air }}\right)$ and solution side Nusselt number $\left(\mathrm{Nu} u_{\text {sol }}\right)$.

Many literatures have investigated $N u$ with different channel aspect ratios based on a constant temperature or heat flux boundary condition. However, according to Huang's comments [31], these values are unable to accurately reflect heat and mass transfer properties in the membrane module since membrane surface boundary condition is neither uniform temperature (concentration) nor uniform heat flux (mass flux). In literature [31], the natural formed boundary layer has been simulated and the values of $N u$ under different channel aspect ratios are derived as given in Table 4.

\section{Table 4}

Fully developed Nusselt numbers $\left(N u_{C, a}\right.$ for air side and $N u_{C, S}$ for solution side) in the parallelplate membrane channel for various aspect ratios [31]

\begin{tabular}{|ccc|}
\hline Aspect ratio & $N u_{C, a}$ & $N u_{C, s}$ \\
\hline 1.0 & 3.12 & 3.41 \\
1.43 & 3.23 & 3.64 \\
2 & 3.48 & 4.05 \\
3 & 4.15 & 4.74 \\
4 & 4.61 & 5.35 \\
8 & 5.79 & 6.41 \\
50 & 7.54 & 7.91 \\
100 & 7.7 & 8.08 \\
$\infty$ & - & - \\
\hline
\end{tabular}

The air and solution side aspect ratios are 27 and 47 respectively in this study, thus the corresponding Nusselt numbers can be calculated: $N u_{\text {air }}=6.58, N u_{\text {sol }}=7.74$ referred to Table 2. The characteristic length of a rectangular channel can be obtained by applying $\mathrm{L}=$ $(4 \mathrm{dH}) /[2(\mathrm{~d}+\mathrm{H})]$, where $d$ is the channel width $(\mathrm{m})$ and $H$ is the channel height $(\mathrm{m})$, which are given in Table 1. For the dehumidifier, the air side and solution side characteristic length are $0.015 \mathrm{~m}$ and $0.008 \mathrm{~m}$ respectively. Subsequently, $h_{\text {air }}$ and $h_{\text {sol }}$ can be derived as 13.16 $\mathrm{W} / \mathrm{m}^{2} \mathrm{~K}$ and $532.13 \mathrm{~W} / \mathrm{m}^{2} \mathrm{~K}$ respectively. Then the $U$ value is calculated as $12.78 \mathrm{~W} / \mathrm{mK}$. For a given $N T U$, the required air mass flow rate can be derived from Eq. (15), correspondingly a series of $m^{*}$ values are obtained. Based on Eq. (6), once the air mass flow rate is determined, a series of solution mass flow rates corresponding to different $m^{*}$ can be obtained as well. All target measurements are shown in Table 5. 
Table 5

299 Target measurements for dimensionless parameter tests

\begin{tabular}{|c|c|c|c|c|c|c|c|c|c|c|c|}
\hline \multicolumn{2}{|c|}{$N T U$} & \multicolumn{2}{|c|}{4} & \multicolumn{2}{c|}{6} & \multicolumn{2}{c|}{8} & \multicolumn{2}{c|}{10} & \multicolumn{2}{c|}{12} \\
\hline$m^{*}$ & $\mathrm{Cr}^{*}$ & $\begin{array}{c}\dot{m}_{\text {sol }} \\
(\mathrm{kg} / \mathrm{s})\end{array}$ & $\begin{array}{c}\dot{V}_{\text {sol }} \\
(\mathrm{l} / \mathrm{min})\end{array}$ & $\begin{array}{c}\dot{m}_{\text {sol }} \\
(\mathrm{kg} / \mathrm{s})\end{array}$ & $\begin{array}{c}\dot{V}_{\text {sol }} \\
(\mathrm{l} / \mathrm{min})\end{array}$ & $\begin{array}{c}\dot{m}_{\text {sol }} \\
(\mathrm{kg} / \mathrm{s})\end{array}$ & $\begin{array}{c}\dot{V}_{\text {sol }} \\
(\mathrm{l} / \mathrm{min})\end{array}$ & $\begin{array}{c}\dot{m}_{\text {sol }} \\
(\mathrm{kg} / \mathrm{s})\end{array}$ & $\begin{array}{c}\dot{V}_{\text {sol }} \\
(\mathrm{l} / \mathrm{min})\end{array}$ & $\begin{array}{c}\dot{m}_{\text {sol }} \\
(\mathrm{kg} / \mathrm{s})\end{array}$ & $\begin{array}{c}\dot{V}_{\text {sol }} \\
(\mathrm{l} / \mathrm{min})\end{array}$ \\
\hline 0.5 & 1.55 & 0.030 & 1.292 & 0.020 & 0.861 & 0.015 & 0.646 & 0.012 & 0.517 & 0.010 & 0.431 \\
\hline 1 & 3.1 & 0.061 & 2.584 & 0.040 & 1.722 & 0.030 & 1.292 & 0.024 & 1.033 & 0.020 & 0.861 \\
\hline 1.5 & 4.65 & 0.091 & 3.875 & 0.061 & 2.584 & 0.045 & 1.938 & 0.036 & 1.550 & 0.030 & 1.292 \\
\hline 2 & 6.2 & 0.121 & 5.168 & 0.081 & 3.445 & 0.061 & 2.584 & 0.048 & 2.067 & 0.040 & 1.722 \\
\hline 2.5 & 7.75 & 0.151 & 6.459 & 0.101 & 4.306 & 0.076 & 3.230 & 0.061 & 2.584 & 0.050 & 2.153 \\
\hline 3 & 9.3 & - & - & 0.121 & 5.167 & 0.091 & 3.875 & 0.073 & 3.100 & 0.061 & 2.584 \\
\hline 3.5 & 10.85 & - & - & 0.141 & 6.028 & 0.106 & 4.521 & 0.085 & 3.617 & 0.071 & 3.014 \\
\hline
\end{tabular}

300

301

302

303

304

305

306

307

308

309

310

311

\subsubsection{Solution property tests}

The next stage of experiment aims to investigate the dehumidifier performance variations with solution inlet temperature $\left(T_{s o l}\right)$ and solution concentration $\left(C_{s o l}\right)$. In this stage, the air inlet condition is set as $30^{\circ} \mathrm{C}$ and $70 \% \mathrm{RH}$, and $N T U$ and $m^{*}$ are set to be 8 and 2 respectively. The testing range of the solution temperature is from $18^{\circ} \mathrm{C}$ to $23^{\circ} \mathrm{C}$. For each $N T U$, three solution concentrations are tested: $33 \%, 36 \%$ and $39 \%$. Since $N T U$ and $m^{*}$ are kept constant, the air and solution flow rates are unchanged. The air mass flow rate is calculated to be $0.030 \mathrm{~kg} / \mathrm{s}$ and the solution mass flow rate is $0.061 \mathrm{~kg} / \mathrm{s}$ (volume flow rate $2.583 \mathrm{l} / \mathrm{min}$ ).

For analysis, the air specific humidity or humidity ratio $(\mathrm{kg} / \mathrm{kg})$ needs to be determined. A correlation between $\mathrm{RH}(\%)$ and absolute humidity (AH) $\left(\mathrm{kg} / \mathrm{m}^{3}\right)$ is derived by Mander [47]:

$A H=\frac{6.112 \times e^{\left[\frac{17.67 \times T}{T+243.5}\right] \times R H \times 2.1674}}{1000(273.15+T)}$

312 Where $T$ is air temperature $\left({ }^{\circ} \mathrm{C}\right)$. Then air specific humidity $W_{\text {air }}(\mathrm{kg} / \mathrm{kg})$ can be calculated 313 by:

$314 \quad W_{\text {air }}=\frac{A H}{\rho_{\text {air }}}$

315 Where $\rho_{\text {air }}$ is air density $\left(\mathrm{kg} / \mathrm{m}^{3}\right)$.

316 The equilibrium specific humidity $\left(W_{\text {sol }}\right)$ is used to calculate both the sensible and latent

317 effectiveness, the relationship between the specific humidity and vapour pressure is given by 318 [40]:

$319 W_{\text {sol }}=0.62198 \frac{P_{v}}{P-P_{v}}$

320 Where $P$ is the atmospheric pressure $(\mathrm{Pa})$ and $P_{v}$ is vapour pressure of desiccant solution $(\mathrm{Pa})$.

321 The equilibrium vapour pressure of desiccant solution is a function of $T_{\text {sol }}$ and $C_{\text {sol }}\left(P_{v}=\right.$ $\left.322 f\left(T_{\text {sol }}, C_{\text {sol }}\right)\right)$, the correlation is given by [49]:

$$
\log P_{v}=K I\left[A-\frac{B}{T-E_{S}}\right]+\left[C-\frac{D}{T-E_{S}}\right]
$$


Where $P_{v}$ is solution equilibrium vapour pressure $(\mathrm{kPa}), \mathrm{K}$ is an electrolyte parameter relating to solute $\left(\mathrm{CaCl}_{2}\right) ; A, B, C, D$ and $E_{s}$ are parameters regarding to solvent (water). Accordingly, a psychrometric chart of $\mathrm{CaCl}_{2}$ is plotted and shown in Fig. 3.

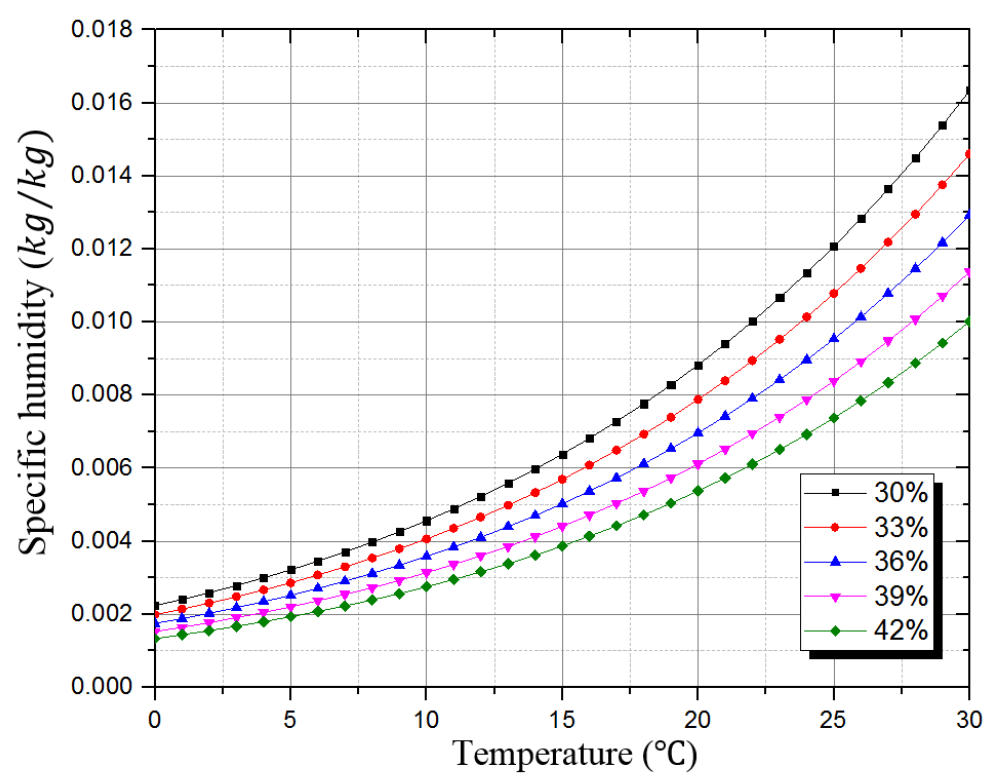

Fig. 3. Psychometric chart of $\mathrm{CaCl}_{2}$

\subsection{Experiment validation based on analytical solution}

Experimental results are validated by comparing to Zhang and Niu's analytical solution for enthalpy exchanger with membrane cores. According to their research, the sensible effectiveness is a function of two dimensionless parameters, NTU and $C_{r}{ }^{*}$. For unmixed cross flow, the function can be presented as [50]:

$\varepsilon_{S}=1-\exp \left[\frac{\exp \left(-N T U^{0.78} C_{r}{ }^{*-1}\right)-1}{N T U^{-0.22} C_{r}{ }^{-1}}\right]$

Similar to sensible effectiveness, the latent effectiveness can be calculated:

$\varepsilon_{l}=1-\exp \left\{\frac{N T U_{m}{ }^{0.22}}{m^{*-1}}\left[\exp \left(-m^{*-1} N T U_{m}{ }^{0.78}\right)-1\right]\right\}$

\section{Results and Discussion}

Forty five experimental tests have been conducted to achieve the objectives of this study. Based on the experimental results, the influences of main operating parameters on the system performance are analysed.

\subsection{Effects of dimensionless parameters}

Two dimensionless parameters, $m^{*}$ and $N T U$, are examined to identify their influences on the dehumidifier performance, experimental results are compared to Zhang's analytical solution [50]. The effectiveness experimental and analytical results under $m^{*}=0.5$ and 1 are shown in Fig.4 and Fig. 5. 


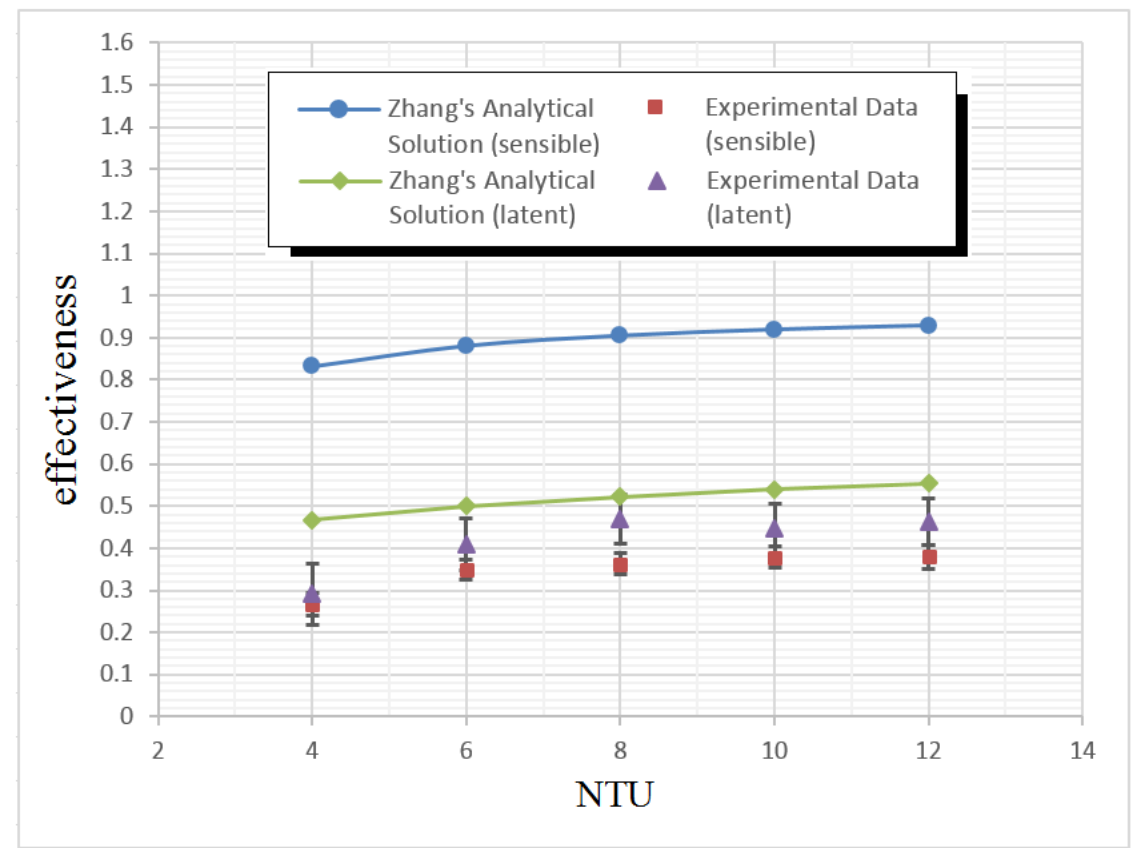

Fig. 4. Experimental and analytical results of sensible and latent effectiveness under $m^{*}=0.5$

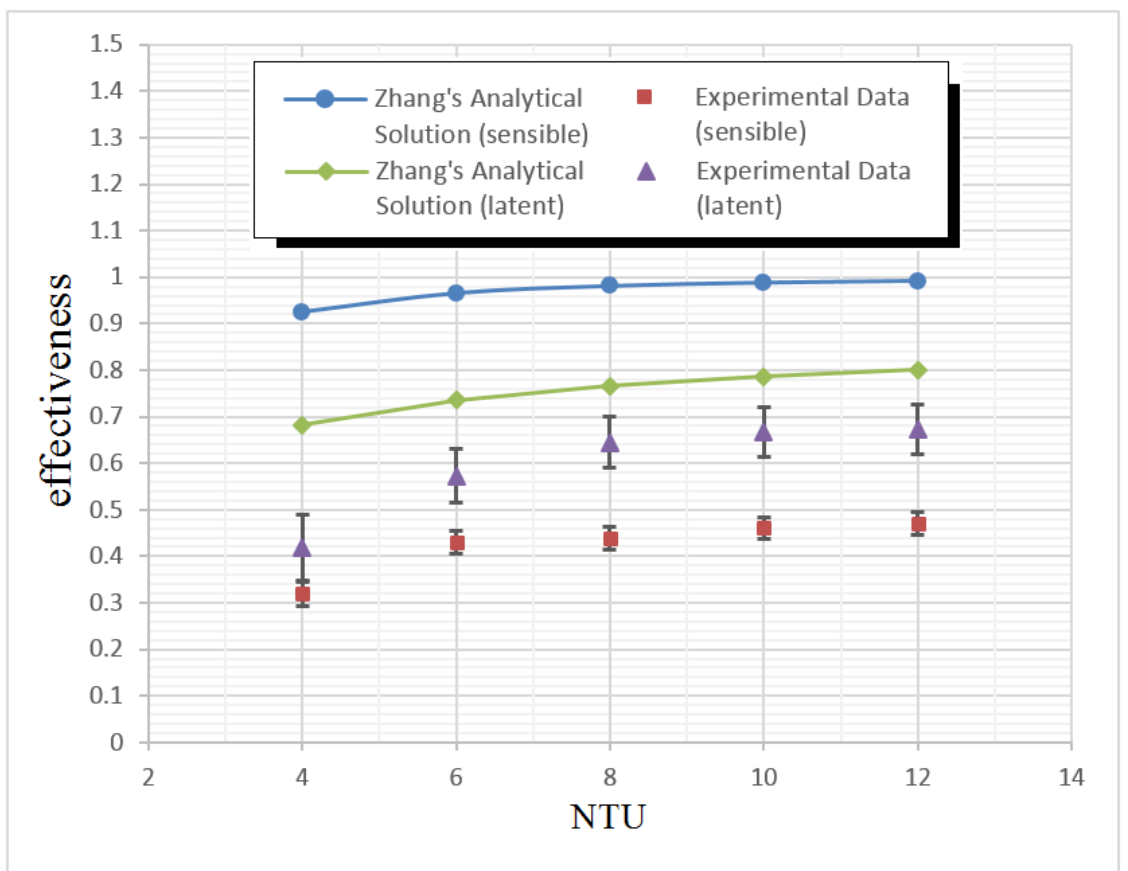

Fig. 5. Experimental and analytical results of sensible and latent effectiveness under $m^{*}=1$

354 The variation trends of experimental data are similar to that of the analytical results for both 355 sensible and latent effectiveness under $m^{*}=0.5$ and 1 . However, the sensible effectiveness 356 discrepancies between them are significant, and the analytical results are higher for both $m^{*}$. 357 The discrepancies between experimental and analytical results are caused by the following 358 assumptions. Firstly, membrane frosting, membrane fouling, and mal-distribution effects are neglected in the analytical models. Secondly, the inhomogeneous membrane properties, such 
as thickness and thermal conductivity, are not considered in the analytical models. Last but not

361 least, the laminar flow is assumed for the air stream in the models to calculate convective heat and mass transfer coefficients. However the amount of heat and mass transfer enhancements are not considered, which could be another source of discrepancy between experimental and

364 analytical results.

365 The variations of the sensible, latent and total effectiveness with $m^{*}$ and NTU are shown in 366 Fig.6. Comparatively the sensible effectiveness is the lowest one among these three effectiveness at the same $m^{*}$ and $N T U$, while the latent effectiveness is the highest one. The maximum values of the sensible, latent and total effectiveness are $0.478,0.561$ and 0.539 respectively when $m^{*}=3.5$ and $N T U=12$. Oppositely, the lowest values of these effectiveness are $0.167,0.181$, and 0.177 when $m^{*}=0.5$ and $N T U=4$. The separate effects of $m^{*}$ and $N T U$ are addressed in the following sections.

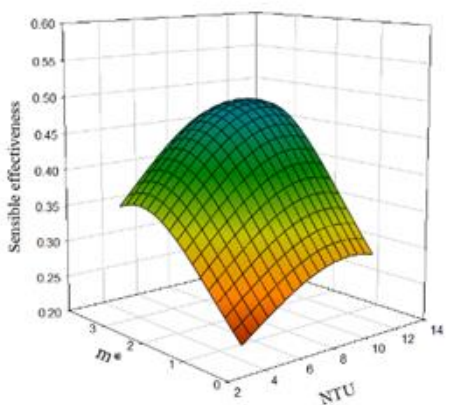

(a)

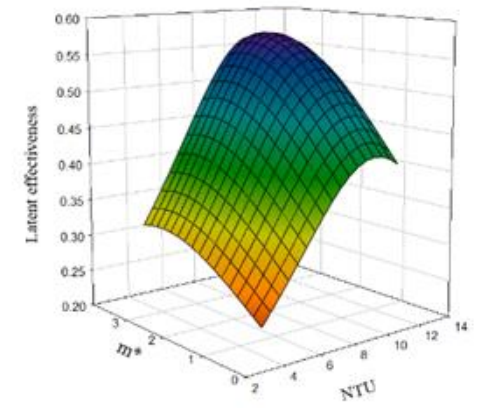

(b)

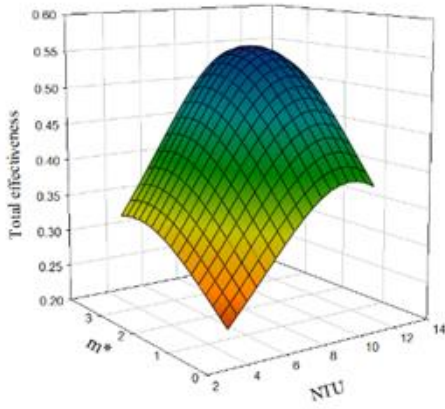

(c)

373

374

375

376

377

378

379

380

381

382

Table 6

Fig. 6. Variations of effectiveness: (a) sensible effectiveness (b) latent effectiveness and (c) total effectiveness with $m^{*}$ and $N T U$

\subsubsection{Effect of mass flow rate ratio $m^{*}$}

The effectiveness under each testing condition can be obtained on the basis of the theories in section 3.1. One example of the effectiveness at $N T U=6$ is given in Table 6 , the variations of the sensible, latent and total effectiveness with $m *$ under different NTUS are shown in Figs. 79.

Sensible, latent and total effectiveness at $N T U=6$ and $C_{\text {sol }}=39 \%$

\begin{tabular}{|c|c|c|c|c|c|c|c|c|c|c|c|}
\hline$m^{*}$ & $C r^{*}$ & $\begin{array}{c}T_{\text {air }, \text { in }} \\
\left({ }^{\circ} \mathrm{C}\right)\end{array}$ & $\begin{array}{c}T_{\text {air out }} \\
\left({ }^{\circ} \mathrm{C}\right)\end{array}$ & $\begin{array}{c}T_{\text {solin }} \\
\left({ }^{\circ} \mathrm{C}\right)\end{array}$ & $\varepsilon_{\text {sen }}$ & $H^{*}$ & $\begin{array}{c}W_{\text {air, }, i n} \\
(\mathrm{~kg} / \mathrm{kg})\end{array}$ & $\begin{array}{c}W_{\text {air,out }} \\
(\mathrm{kg} / \mathrm{kg})\end{array}$ & $\begin{array}{c}W_{\text {solin }} \\
(\mathrm{kg} / \mathrm{kg})\end{array}$ & $\varepsilon_{\text {lat }}$ & $\varepsilon_{\text {total }}$ \\
\hline 0.5 & 1.565 & 30.293 & 28.710 & 19.909 & 0.249 & 2.874 & 0.0180 & 0.0152 & 0.0061 & 0.3093 & 0.2937 \\
\hline 1 & 3.13 & 30.045 & 27.788 & 20.162 & 0.329 & 3.050 & 0.0182 & 0.0146 & 0.0062 & 0.3728 & 0.3622 \\
\hline 1.5 & 4.695 & 30.416 & 27.952 & 21.178 & 0.375 & 3.173 & 0.0183 & 0.0145 & 0.0066 & 0.3972 & 0.3919 \\
\hline 2 & 6.26 & 29.981 & 27.178 & 20.564 & 0.404 & 3.158 & 0.0182 & 0.0138 & 0.0063 & 0.4389 & 0.4305 \\
\hline 2.5 & 7.825 & 29.652 & 26.894 & 20.804 & 0.425 & 3.265 & 0.0180 & 0.0137 & 0.0064 & 0.4446 & 0.4399 \\
\hline 3 & 9.3 & 29.468 & 26.835 & 20.890 & 0.423 & 3.416 & 0.0182 & 0.0139 & 0.0065 & 0.4361 & 0.4332 \\
\hline 3.5 & 10.85 & 29.790 & 26.701 & 20.369 & 0.434 & 2.981 & 0.0175 & 0.0133 & 0.0063 & 0.4435 & 0.4411 \\
\hline
\end{tabular}




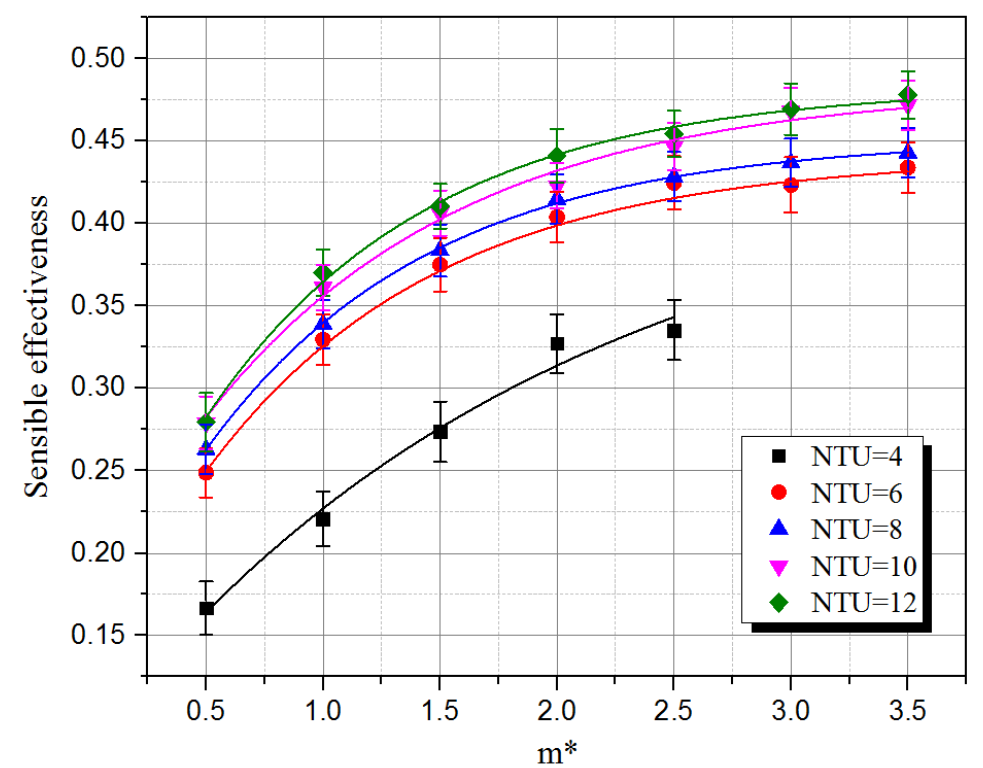

385

Fig. 7. Sensible effectiveness variations with $m^{*}$ under different NTUS 386

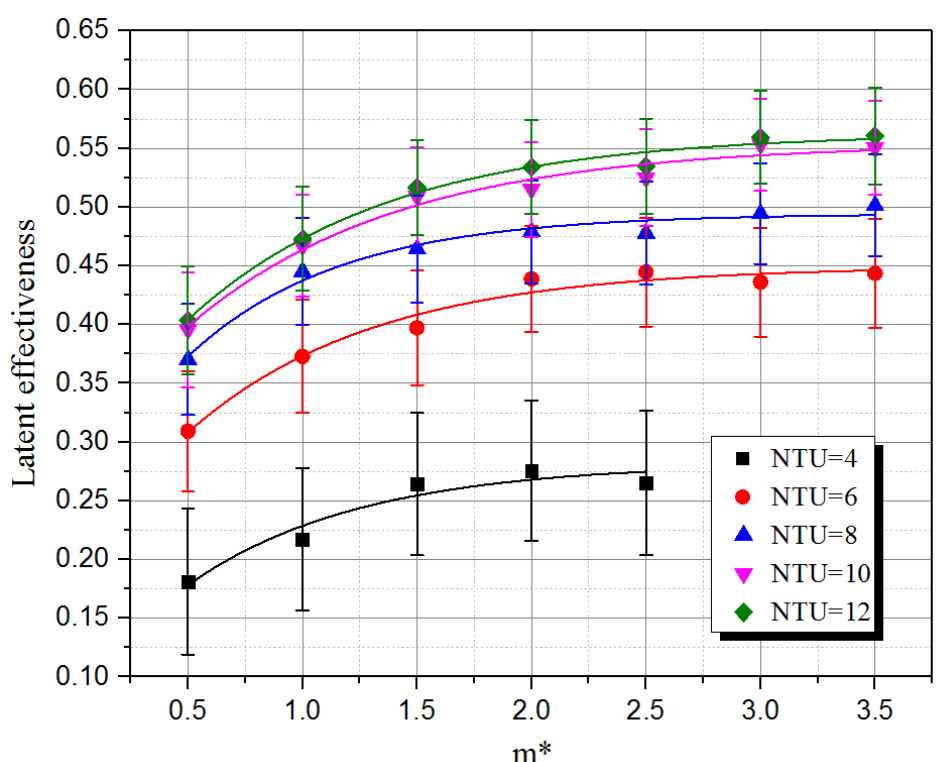

Fig. 8. Latent effectiveness variations with $m^{*}$ under different $N T U S$ 


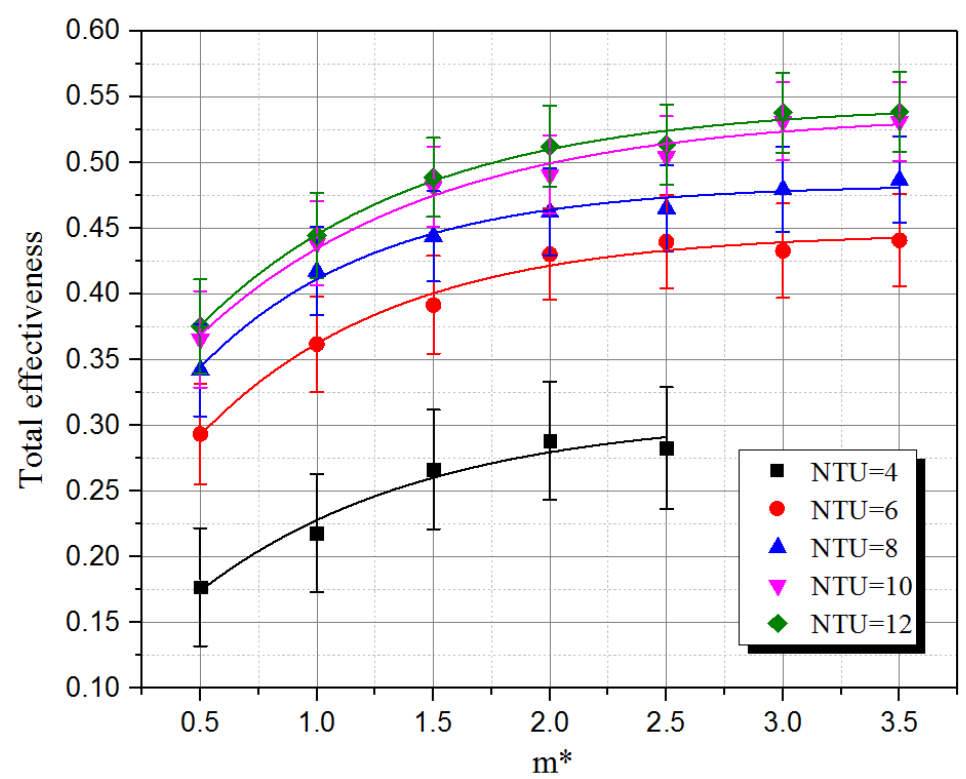

390

Fig. 9. Total effectiveness variation with $m^{*}$ under different $N T U S$

It is evident that the sensible, latent and total effectiveness increase with $m^{*}$. For instance, at $N T U=6$, the sensible effectiveness increases from 0.249 to 0.434 as $m^{*}$ changes from 0.5 to 3.5. In the meanwhile, the latent and total effectiveness increase from 0.309 to 0.444 and from 0.294 to 0.441 respectively. However, the gradients of their increases become less moderate when $m^{*}$ is in the range of 0.5 to 2 , and a slight variation is observed once $m^{*}$ is over 2. Similar effects of mass flow rate ratio are presented in literature [29], these effectiveness (sensible, latent and total) reach the maximum values and the dehumidification system has the highest efficiency when heat capacitance ratio $\mathrm{Cr}^{*}$ reaches a critical value $\mathrm{Cr}_{c r i t}^{*}$ (around 6.26). These effectiveness increase with $C r^{*}$ and is more sensitive to $C r^{*}$ at lower $C r^{*}[51,52]$. As the heat capacitance ratio $\mathrm{Cr}^{*}$ is proportional to the mass flow rate ratio $m^{*}$, the effectiveness variations with $m^{*}$ are similar to that with $C r^{*}$. Therefore a similar critical value of $m^{*}$ is defined as $m_{c r i t}^{*}$, which is 2 in this study. A similar trend obtained from numerical modelling is found in literatures [24, 25], both the sensible and latent effectiveness increase with $m^{*}$ when $m^{*}<1$, but they are nearly constant when $m^{*} \geq 1$. So in most cases, it is desirable to maintain the dehumidification system operating at a condition where $m^{*}$ is equal to $m_{c r i t}^{*}$. It is also worth mentioning that at a low $N T U$, all effectiveness are very low especially for the latent effectiveness. For instance, at $N T U=4$, the latent effectiveness is in the range of 0.181 to 0.265. Thus there is hardly benefit to increase $\mathrm{m}^{*}$ or $\mathrm{Cr}^{*}$ for performance improvement at low NTU. On the other hand, the increase rate of the sensible effectiveness is more significant compared with that of the latent effectiveness at the same $N T U$. For instance, at $N T U=6$, the sensible effectiveness increases by $74 \%$ when $m^{*}$ increases from 0.5 to 3.5 , while the latent 
effectiveness only rises by $43 \%$. Similarly, at $N T U=8$, the sensible effectiveness increases by

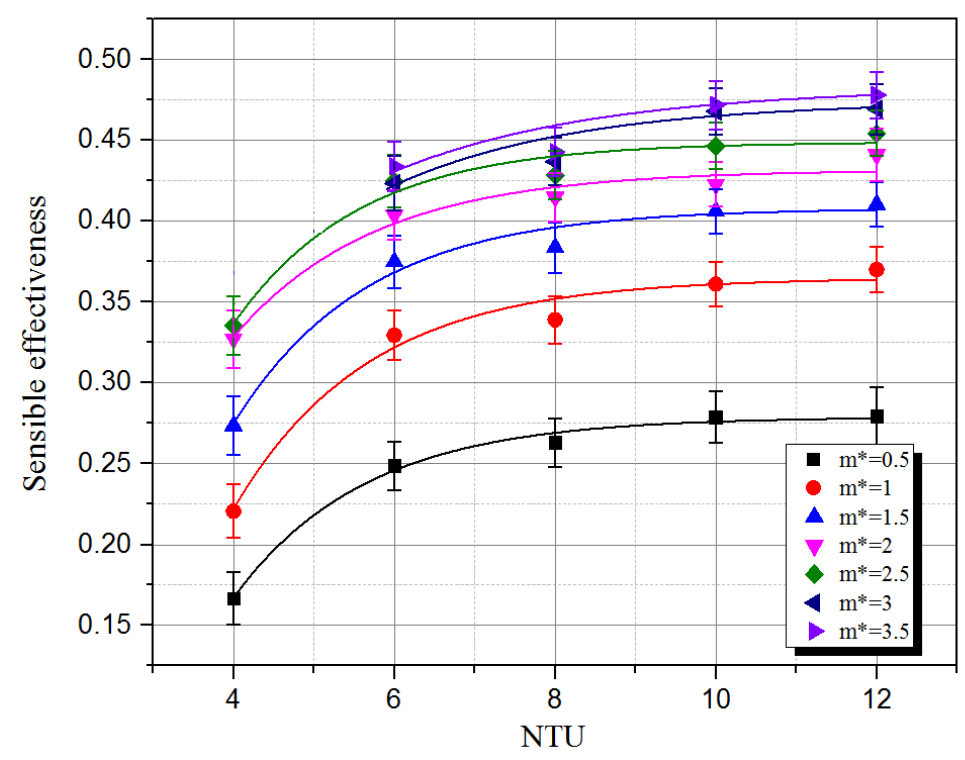

430

Fig. 10. Sensible effectiveness variations with $N T U$ under different $m^{*}$

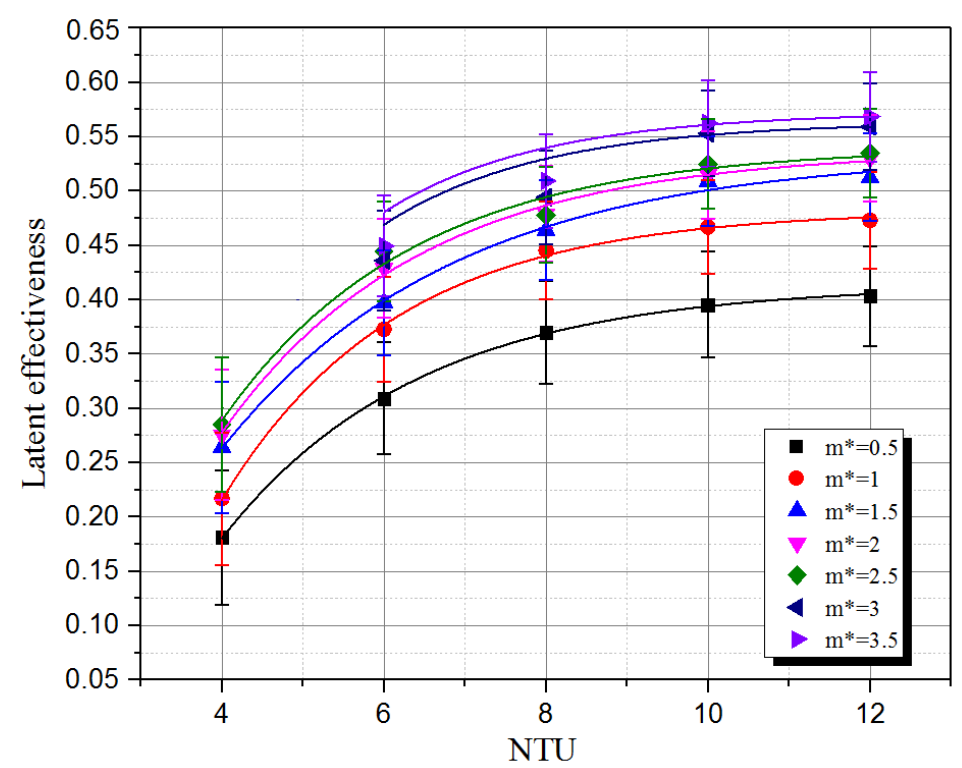




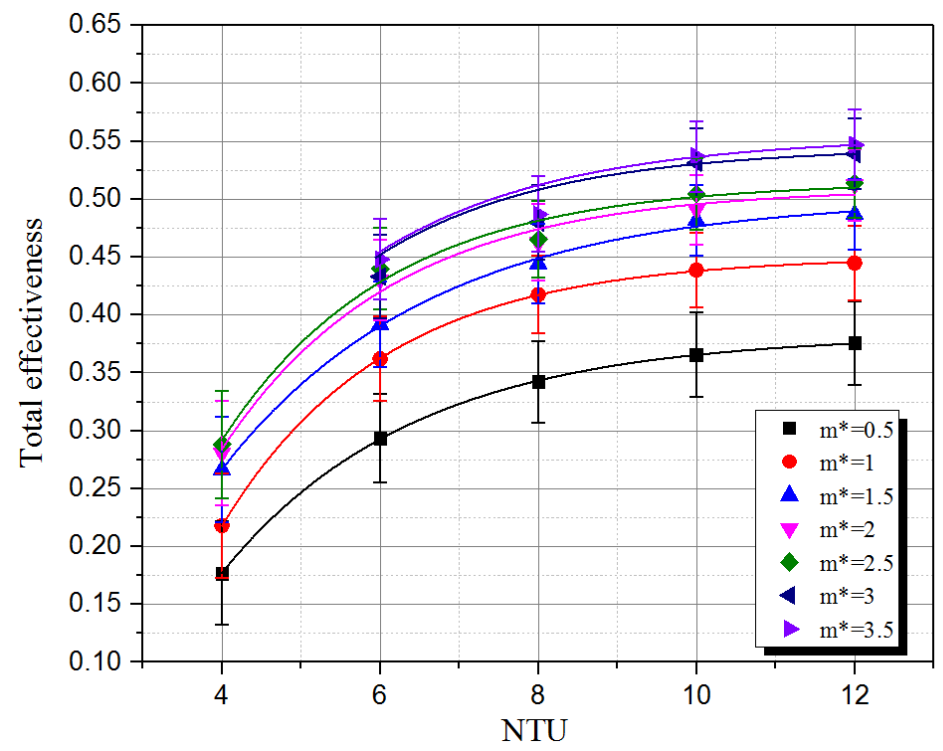

Fig. 12. Total effectiveness variations with $N T U$ under different $m^{*}$

The variations of three effectiveness with NTU under different $m^{*}$ are presented in Figs. 10-12. Compared to the flow rate, the non-dimensional group $N T U$ is a comprehensive indicating parameter because it eliminates the impact of channel geometric properties. Significant increases of the sensible, latent and total effectiveness with $N T U$ can be found when $N T U$ is in the range of 4 to 6 , and the associated gradients reduce from $N T U=8$ and at the end the gradients are becoming negligible. These trends indicate that at a high NTU, the effectiveness improvements are no longer limited by $N T U$, in other words, increasing $N T U$ will not enhance the system efficiency. Similar to $C r_{c r i t}^{*}$ and $m_{c r i t}^{*}$ mentioned previously, a critical NTU exists and is defined as $N T U_{c r i t}$. All effectiveness reach the maximum as NTU reaches the critical value $N T U_{\text {crit }}$, which is 8 in this experiment. These results show a good agreement with numerical simulation data of a cross-flow air-to-air enthalpy exchanger with hydrophilic membrane cores in literature [53]. The effectiveness of the enthalpy exchanger increase with $N T U$ when $N T U$ is in the range of 0 to 5 and the increase gradients become moderate when $N T U$ is greater than 5. A similar effectiveness variation trend is indicated in literature [39] as well, both the supply air humidity ratio and temperature decrease as NTU increases from 1 to 10. However, less significant effects on the system performance are noted when NTU > 10 . 


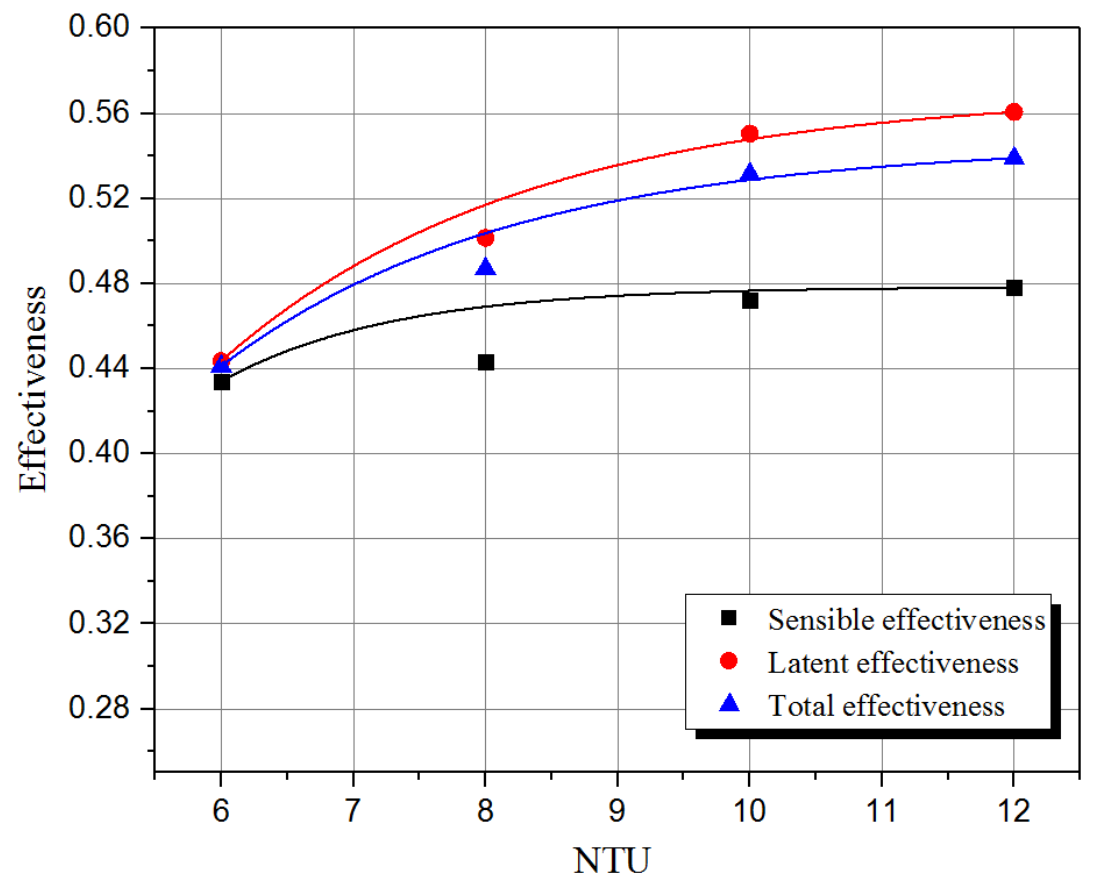

456

Fig. 13. Effectiveness variations with $N T U$ under $m^{*}=3.5$

The variations of the sensible, latent and total effectiveness with $N T U$ at $m^{*}=3.5$ are plotted in Fig. 13. The maximum sensible effective is around 0.478 at $N T U=12$, while the maximum latent and total effectiveness are approximately 0.561 and 0.539 respectively. At the same $m^{*}$, the latent effectiveness is higher than the sensible effectiveness. One reason restricting the sensible effectiveness is high cold water temperature. The sensible effectiveness is limited seriously by the inlet solution temperature, which depends on the cold water temperature in the system. Another reason is that the solution cannot be evenly spayed to the membrane surface, especially at high $N T U$ and low $m^{*}$, for example when the solution mass flow rate is very low. Therefore, spray nozzle with a larger volumetric spray distribution pattern should be used to improve dehumidification performance. The latent effectiveness is strongly affected by the membrane vapour diffusion resistance, which is related to membrane water permeability. Thus the latent effectiveness can be improved by increasing the membrane water permeability [54]. This can be implemented by utilizing porous membranes or increasing membrane surface area $[28,29]$. However, the porous membrane that has lower vapour diffusion resistance may lead to the problem of droplets carryover. Additionally, the bigger size membrane results in higher air pressure drop, and thus more fan power is required. Moreover, the crystallization of the desiccant would considerably affect heat and mass transfer in the dehumidifier by changing the membrane water permeability [28]. As a result, investigations in the optimum membrane vapour diffusivity with considerations of latent effectiveness, carryover and fan power are needed for further research. 
To sum up, both the sensible and latent effectiveness of dehumidifier reach their maximum values at $m_{c r i t}^{*}=2$ and $N T U_{c r i t}=8$, and the gradients of their increases hardly change as $m^{*}$ is over $m_{c r i t}^{*}$ and $N T U$ is over $N T U_{\text {crit }}$. The sensible effectiveness can be improved by utilizing spray nozzle with a larger volumetric spray distribution pattern, and the latent effectiveness can be enhanced by increasing membrane water permeability.

\subsection{Effects of solution properties}

The influences of desiccant solution properties on the system performance are investigated, the main parameters of the solution properties are solution concentration $C_{\text {sol }}$ and inlet temperature $T_{\text {sol,in. }}$. The variations of the sensible, latent and total effectiveness with $C_{\text {sol }}$ and $T_{\text {sol,in }}$ are presented in Fig. 14, with $N T U$ and $m^{*}$ set at 8 and 2 respectively. The sensible effectiveness reaches the maximum value of 0.446 when $C_{\text {sol }}=33 \%$ and $T_{\text {sol,in }}=18^{\circ} \mathrm{C}$, and its minimum value is 0.424 when $C_{\text {sol }}=39 \%$ and $T_{\text {sol,in }}=23^{\circ} \mathrm{C}$. By contrast, the maximum latent effectiveness is 0.538 at $C_{\text {sol }}=39 \%$ and $T_{\text {sol, in }}=18^{\circ} \mathrm{C}$, and its minimum value is 0.372 at $C_{\text {sol }}$ $=33 \%$ and $T_{\text {sol,in }}=23^{\circ} \mathrm{C}$. For the total effectiveness, its maximum value is 0.510 at $C_{\text {sol }}=39 \%$ and $T_{\text {sol,in }}=18^{\circ} \mathrm{C}$, and the minimum one is 0.389 when $C_{\text {sol }}=33 \%$ and $T_{\text {sol, in }}=23^{\circ} \mathrm{C}$. The effects of $C_{s o l}$ and $T_{\text {sol,in }}$ on the effectiveness are analysed separately in the following sections.

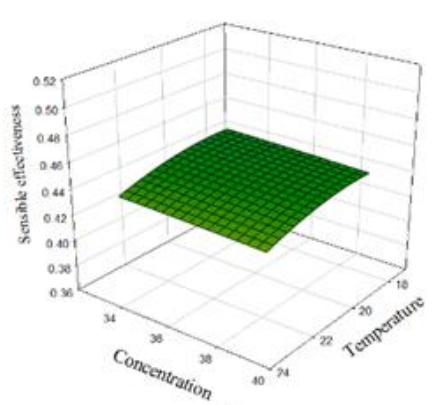

(a)

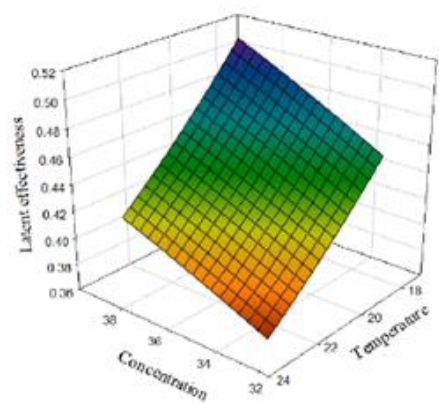

(b)

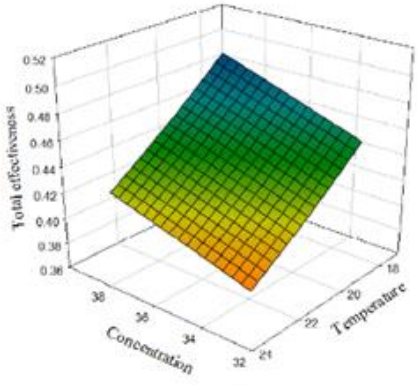

(c)

Fig. 14. Variations of effectiveness: (a) sensible effectiveness (b) latent effectiveness and (c) total effectiveness with $C_{s o l}$ and $T_{\text {sol,in }}$ 


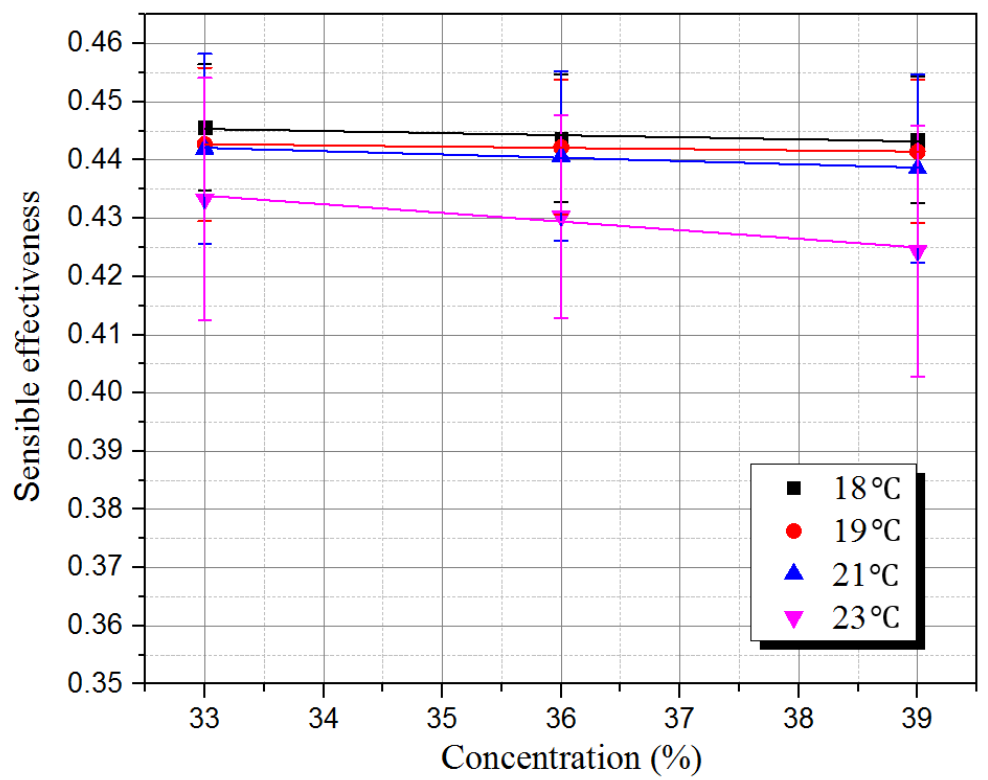

Fig. 15. Sensible effectiveness variations with $C_{\text {sol }}$ under different $T_{\text {sol,in }}$

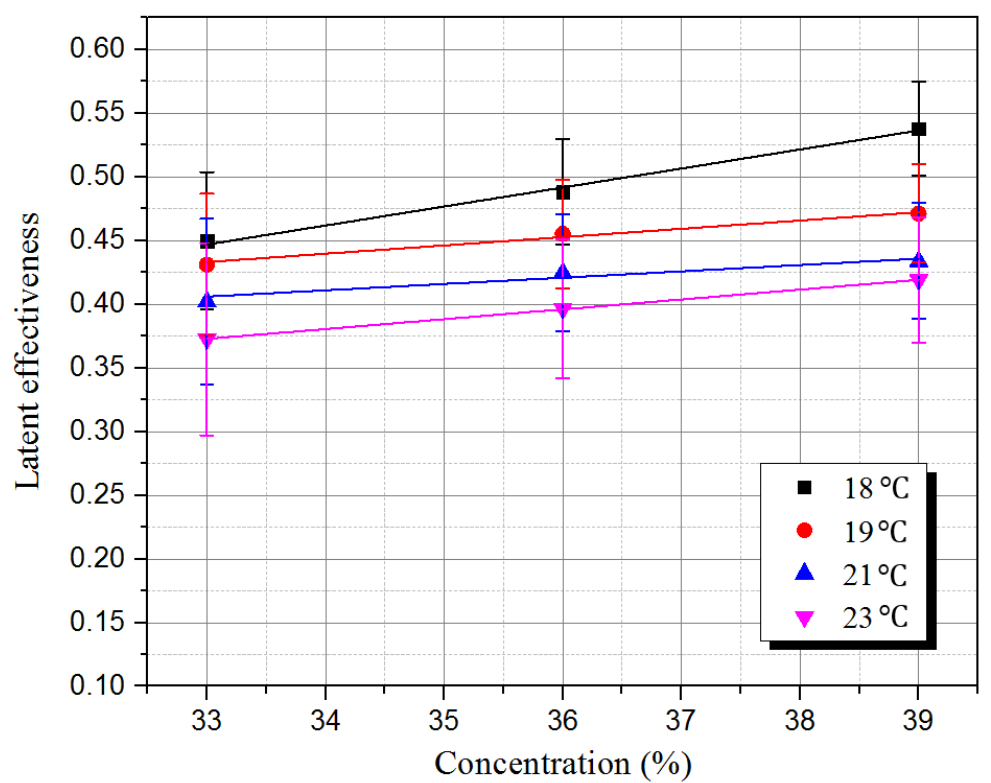

Fig. 16. Latent effectiveness variations with $C_{\text {sol }}$ under different $T_{\text {sol,in }}$ 


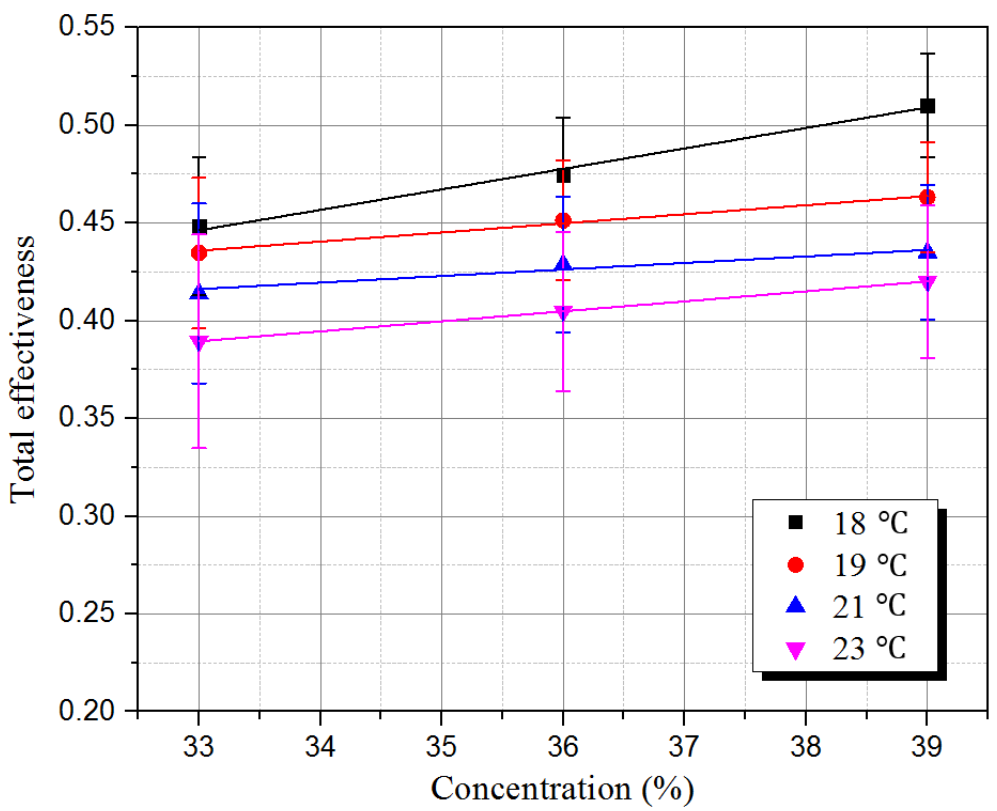

514

Fig. 17. Total effectiveness variations with $C_{\text {sol }}$ under different $T_{\text {sol,in }}$

The solution concentration has a significant effect on the system performance since it is directly related to the surface vapour pressure. The variations of the effectiveness with $C_{s o l}$ are shown in Figs. 15-17, it can be seen that increasing concentration has different impacts on the sensible, latent and total effectiveness. The sensible effectiveness is negatively related to $C_{s o l}$, while the latent and total effectiveness are positively related to $C_{\text {sol }}$. At the inlet solution temperature of $21^{\circ} \mathrm{C}$, the sensible effectiveness decreases from 0.442 to 0.439 as the solution concentration increases from $33 \%$ to $39 \%$, while the latent and total effectiveness increase from 0.402 to 0.434 and from 0.414 to 0.435 respectively. The sensible effectiveness is insensitive to the solution concentration as only a slight decrease with the concentration can be seen. This is because the increase of latent effectiveness would lead to more latent heat to be released to the air channel during condensation on the solution side membrane surface. In the meanwhile, the convective heat transfer coefficient on the air side is relatively low, as a result, the sensible effectiveness would be slightly decreased. For instance, at $T_{\text {sol,in }}=18^{\circ} \mathrm{C}$, the sensible effective decreases by $0.67 \%$ when $C_{\text {sol }}$ increases from $33 \%$ to $39 \%$. Meanwhile, the latent and total effectiveness increase by $19.6 \%$ and $13.8 \%$ respectively. 
539

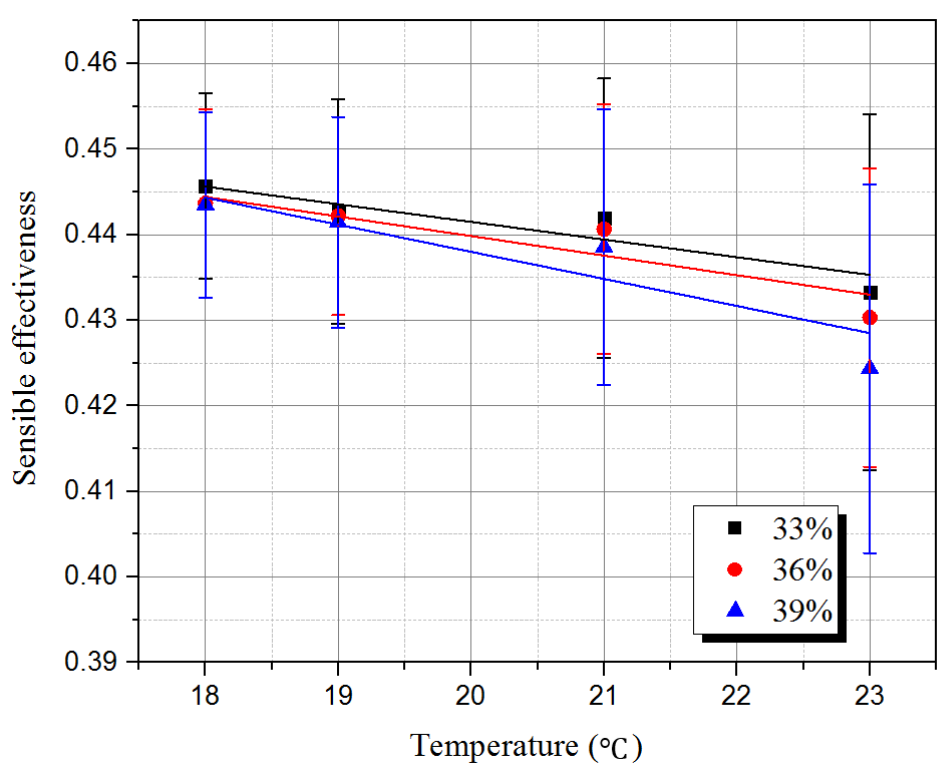

540

Fig. 18. Sensible effectiveness variations with $T_{\text {sol,in }}$ under different $C_{\text {sol }}$ 542

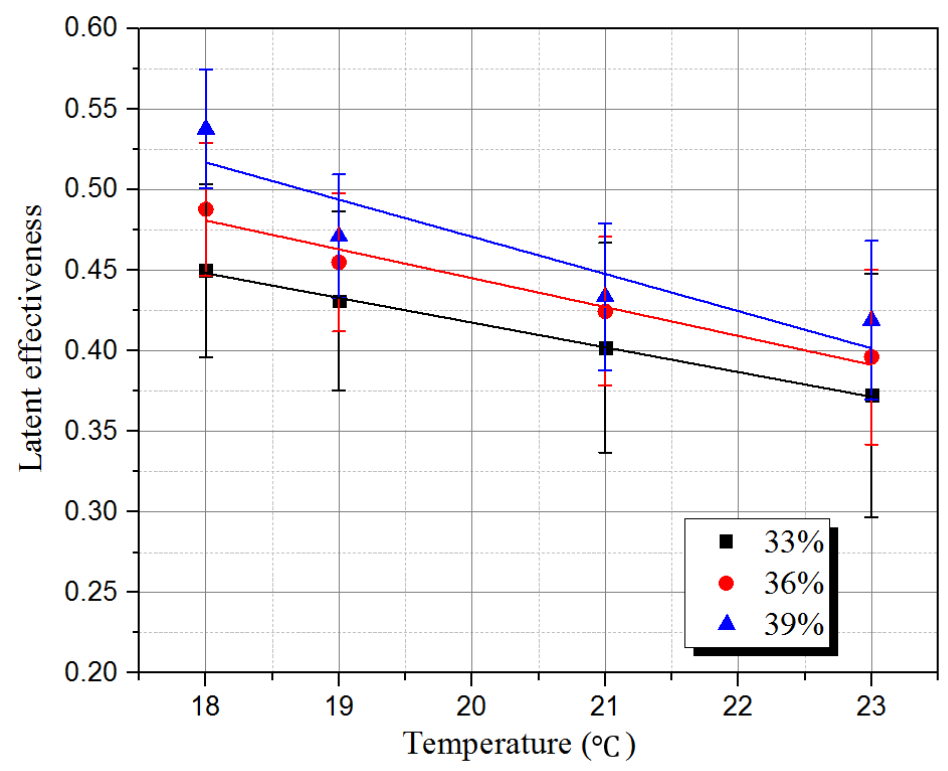

Fig. 19. Latent effectiveness variations with $T_{\text {sol,in }}$ under different $C_{\text {sol }}$ 


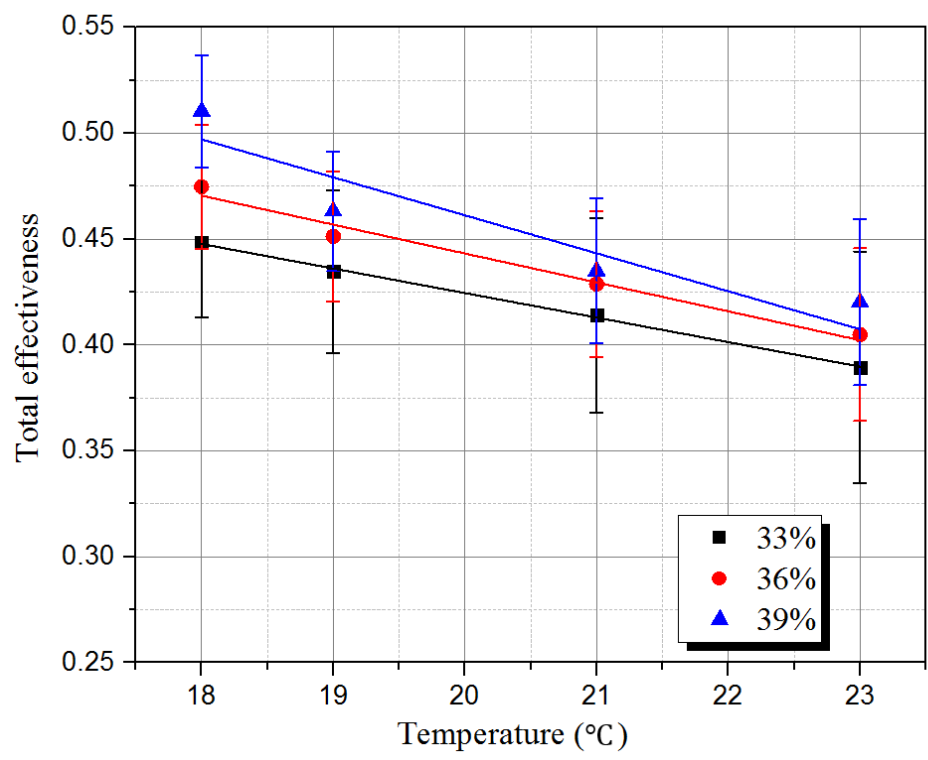

Fig. 20. Total effectiveness variations with $T_{\text {sol,in }}$ under different $C_{\text {sol }}$

The solution inlet temperature $T_{\text {sol,in }}$ is another key parameter influencing the system performance as it is related to the surface vapour pressure as well. It is clearly reflected in Figs. 18-20 that unlike the impacts of $C_{\text {sol }}$, these effectiveness decrease accordingly with the solution inlet temperature. This is attributed to the reduction of vapour pressure at the solution side. Similar effects are stated in literature [53], the lower solution inlet temperature leads to the lower conditioned air temperature and humidity ratio, which contributes to the higher sensible and latent effectiveness.

The impact of $T_{\text {sol,in }}$ on the sensible effectiveness is far less than that on the latent one. This means that the sensible effectiveness is also insensitive to $T_{\text {sol,in }}$. Similar to the impact of $C_{s o l}$, this is mainly due to the fact that the increasing of latent effectiveness would contribute to more latent heat to be released to the air channel during the process of condensation. As a result, the sensible effectiveness is weakened. For instance, at $C_{s o l}=33 \%$, the sensible effectiveness decreases by $2.9 \%$ as the solution inlet temperature increases from $18^{\circ} \mathrm{C}$ to $23^{\circ} \mathrm{C}$, while the latent and total effectiveness reduce by $17.3 \%$ and by $13.1 \%$ respectively.

It is also found that at different concentrations, the solution temperature has different effects on the effectiveness. The higher the solution concentration, the more significant effect the solution temperature has. As the solution temperature reduces from $23^{\circ} \mathrm{C}$ to $18^{\circ} \mathrm{C}$, the sensible effectiveness increases by $4.5 \%$ at the solution concentration of $39 \%$, by $3.3 \%$ and $3.0 \%$ at the solution concentrations of $36 \%$ and $33 \%$ respectively. In terms of the latent effectiveness, when the solution temperature decreases from $23^{\circ} \mathrm{C}$ to $18^{\circ} \mathrm{C}$, the latent effectiveness rises by $28.4 \%$ at the solution concentration of $39 \%$, by $23.2 \%$ at the concentration of $36 \%$ and by $21 \%$ at the 
concentration of 33\%. Thus decreasing solution temperature would be a more effective way for

571 the performance improvement with the high concentration solution.

572 To sum up, the system can achieve higher latent effectiveness at lower solution temperature

573 and higher concentration, which is clearly noted in Fig. 14 (b). The solution temperature and

574 concentration have more significant influences on the latent effectiveness compared with the

575 sensible effectiveness. As shown in Fig. 14 (a), the sensible effectiveness hardly varies with the

576 solution temperature and concentration. A similar statement is presented in literature [53],

577 which indicates the sensible effectiveness of a cross-flow membrane-based enthalpy exchanger

578 is not sensitive to its operating conditions. The system dehumidification performance can be

579 improved by increasing the solution concentration and lowering the solution inlet temperature.

580 Comparatively, increasing the solution concentration is preferred in the liquid desiccant system,

581 because more energy is needed to achieve lower solution inlet temperature. However, the use

582 of highly concentrated solution could cause the crystallization problem, which leads to fluid

583 mal-distribution, blockage of the channels, high pumping pressure and membrane fouling.

584 Therefore, the solution properties need to be assessed to avoid crystallization risk [54].

585

586 5. Conclusions

587 The performance evaluation of a cross-flow membrane-based dehumidification system with

$588 \mathrm{CaCl}_{2}$ desiccant solution is carried out experimentally in this study. The influences of main 589 operating parameters on dehumidification effectiveness (sensible, latent and total effectiveness)

590 have been assessed, which include number of heat transfer units (NTU), solution to air mass 591 flow rate ratio $\left(m^{*}\right)$, solution inlet temperature $\left(T_{\text {sol,in }}\right)$ and concentration $\left(C_{\text {sol }}\right)$. Following key 592 points can be concluded based on the experimental results:

593 - The sensible, latent and total effectiveness increase with $m^{*}$ and $N T U$. However, the 594 increase gradients hardly change when $m^{*}$ and $N T U$ are over $m_{\text {crit }}^{*}$ and $N T U_{\text {crit }}$ 595 respectively.

596 - It is desirable to operate the system at the critical condition where $m_{\text {crit }}^{*}=2$ 597 and $N T U_{\text {crit }}=8$.

- The sensible effectiveness is the lowest one among the three effectiveness at the same $m^{*}$ and $N T U$, while the latent effectiveness is the highest one. The increase rate with $N T U$ in the sensible effectiveness is more significant compared to that in the latent effectiveness.

- The sensible effectiveness can be improved by utilizing spray nozzle with a larger volumetric spray distribution pattern, while the latent effectiveness can be increased by enhancing membrane water permeability. 
- Both the latent and total effectiveness increase with the solution concentration while the sensible effectiveness nearly has no variation. All effectiveness can be improved by decreasing the solution inlet temperature.

- Increasing solution concentration is a preferable way to improve dehumidification efficiency with less energy consumption. However, the operating condition needs to be assessed to avoid crystallization risk for high concentrated solution.

Future research work will be conducted to explore the impacts of various liquid desiccants on the system performance.

\section{Acknowledgements}

The work was supported by The Royal Society for International Exchange Exchanges Scheme - 2015 China (NSFC) Cost share.

\section{Appendix}

Absolute uncertainties for dimensionless parameter tests are given in Table A.1.

Table A.1

Absolute uncertainties for dimensionless parameter tests

\begin{tabular}{|c|c|c|c|c|c|c|c|c|c|}
\hline$m^{*}$ & $N T U$ & $\delta_{\text {sen }}$ & $\delta_{\text {lat }}$ & $\delta_{\text {tot }}$ & $m^{*}$ & $N T U$ & $\delta_{\text {sen }}$ & $\delta_{\text {lat }}$ & $\delta_{\text {tot }}$ \\
\hline 0.5 & 4 & 0.01615 & 0.06213 & 0.044883 & 3 & 8 & 0.014702 & 0.042904 & 0.03229 \\
\hline 1 & 4 & 0.016724 & 0.060976 & 0.044846 & 3.5 & 8 & 0.014907 & 0.042307 & 0.032089 \\
\hline 1.5 & 4 & 0.018229 & 0.060499 & 0.045483 & 0.5 & 10 & 0.015979 & 0.049164 & 0.036836 \\
\hline 2 & 4 & 0.017755 & 0.059658 & 0.044874 & 1 & 10 & 0.013815 & 0.043305 & 0.031994 \\
\hline 2.5 & 4 & 0.018229 & 0.061614 & 0.046308 & 1.5 & 10 & 0.013669 & 0.041306 & 0.030547 \\
\hline 0.5 & 6 & 0.014997 & 0.051354 & 0.038294 & 2 & 10 & 0.0141 & 0.041523 & 0.030913 \\
\hline 1 & 6 & 0.015058 & 0.048103 & 0.036417 & 2.5 & 10 & 0.014249 & 0.041133 & 0.03077 \\
\hline 1.5 & 6 & 0.016149 & 0.04873 & 0.037254 & 3 & 10 & 0.01429 & 0.039403 & 0.029659 \\
\hline 2 & 6 & 0.015396 & 0.045433 & 0.034703 & 3.5 & 10 & 0.015076 & 0.039804 & 0.030384 \\
\hline 2.5 & 6 & 0.016223 & 0.046097 & 0.035492 & 0.5 & 12 & 0.017679 & 0.0459 & 0.035811 \\
\hline 3 & 6 & 0.016694 & 0.046315 & 0.036027 & 1 & 12 & 0.014121 & 0.044403 & 0.03252 \\
\hline 3.5 & 6 & 0.015134 & 0.046261 & 0.03485 & 1.5 & 12 & 0.013709 & 0.04044 & 0.030115 \\
\hline 0.5 & 8 & 0.014984 & 0.048837 & 0.03626 & 2 & 12 & 0.016475 & 0.041759 & 0.032289 \\
\hline 1 & 8 & 0.014602 & 0.045189 & 0.033609 & 2.5 & 12 & 0.014109 & 0.040556 & 0.030278 \\
\hline 1.5 & 8 & 0.015736 & 0.045647 & 0.034502 & 3 & 12 & 0.015603 & 0.039519 & 0.030438 \\
\hline 2 & 8 & 0.014731 & 0.04392 & 0.032928 & 3.5 & 12 & 0.014506 & 0.040724 & 0.030244 \\
\hline 2.5 & 8 & 0.01483 & 0.044008 & 0.033099 & & & & & \\
\hline & & & & & & & & & \\
\hline
\end{tabular}


Absolute uncertainties for solution property tests are given in Table A.2.

623

624

625

626

627

628

629

630

631

632

633

634

635

636

637

638

639

640

641

642

643

Table A.2

Absolute uncertainties for solution property tests

\begin{tabular}{|c|c|c|c|c|}
\hline$T_{\text {sol,in }}\left({ }^{\circ} \mathrm{C}\right)$ & $C_{\text {sol }}(\%)$ & $\delta_{\text {sen }}$ & $\delta_{\text {lat }}$ & $\delta_{\text {tot }}$ \\
\hline 18.142 & 33 & 0.01084 & 0.053881 & 0.035335 \\
\hline 18.058 & 36 & 0.010978 & 0.04145 & 0.029275 \\
\hline 18.103 & 39 & 0.010862 & 0.037063 & 0.026455 \\
\hline 19.498 & 33 & 0.013142 & 0.055662 & 0.038496 \\
\hline 18.903 & 36 & 0.011601 & 0.042919 & 0.030657 \\
\hline 19.396 & 39 & 0.012323 & 0.038406 & 0.028218 \\
\hline 21.395 & 33 & 0.016322 & 0.065111 & 0.045988 \\
\hline 20.975 & 36 & 0.014607 & 0.046138 & 0.034533 \\
\hline 21.190 & 39 & 0.016092 & 0.04561 & 0.034219 \\
\hline 23.220 & 33 & 0.020806 & 0.075518 & 0.054722 \\
\hline 22.999 & 36 & 0.017421 & 0.054272 & 0.04077 \\
\hline 23.388 & 39 & 0.02154 & 0.049277 & 0.039237 \\
\hline
\end{tabular}

\section{References}

[1] Perez-Lombard L, Ortiz J, Pout C. A review on buildings energy consumption information, Energy Build. 2008; 40:394 - 398.

[2] Huang SM, Zhang LZ. Researches and trends in membrane-based liquid air dehumidification. Renewable and Sustainable Energy Reviews 2013; 28:425-440.

[3] Mahmud K, Mahmood GI, Simonson CJ and Besant RW. Performance testing of a counter-cross-flow run-around membrane energy exchanger (RAMEE) system for HVAC applications. Energy Build. 2010; 42(7):1139-1147

[4] Grossman G. Solar cooling, dehumidification and air-conditioning. Encyclopedia of Energy 2004:575-85

[5] T. Welch, in: H. Carwarardine, K. Butcher (Eds.), CIBSE Knowledge Series: KS13Refrigeration, CIBSE Publications, London, UK, 2008.

[6] Ouazia B, Barhoun H, Haddad K, Armstrong M, Marchand RG, Szadkowski F, Desiccant-evaporative cooling system for residential buildings, in: 12th Canadian Conference on Building Science and Technology, Institute for Research in Construction: Montreal, QC, 2009. 
[7] The CIBSE Journal CPD Programme: liquid desiccant for dehumidification in building air conditioning systems.

[8] Daou K, Wang RZ, Xia ZZ. Desiccant cooling air conditioning: a review. Renew Sustain Energy Rev 2006; 10:55-77.

[9] Mei L, Dai YJ. A technical review on use of liquid-desiccant dehumidification for airconditioning application. Renew Sustain Energy Rev 2008; 12:662-89.

[10] Jain S, Bansal PK, Performance analysis of liquid desiccant dehumidification systems, Int. J. Refrig. 2007; 30(5):861 - 872.

[11] Abdel-Salam M, Ge GM, Fauchoux M, Besant RW, Simonson CJ. State-of-the-art in liquid-to-air membrane energy exchangers (LAMEEs): A comprehensive review. Renewable and Sustainable Energy Reviews. 2014; 39:700-728.

[12] Woods J, Kozubal E. Heat transfer and pressure drop in spacer-filled channels for membrane energy recovery ventilators. Appl Therm Eng 2013; 51:770-80.

[13] Dai YJ, Wang RZ, Zhang HF, Yu JD. Use of liquid desiccant cooling to improve the performance of vapour compression air conditioning. Appl Therm Eng 2001; 21:1185202.

[14] Pietruschka D, Eicker U, Huber M, Schumacher J. Experimental performance analysis and modelling of liquid desiccant cooling systems for air conditioning in residential buildings. Int J Refrig 2006; 29:110-24.

[15] Tu M, Ren CQ, Zhang LA, Shao JW. Simulation and analysis of novel liquid desiccant air-conditioning system. Appl Therm Eng 2009; 29:2417-25.

[16] Zhang XR, Zhang LZ, Liu HM, Pei LX. One-step fabrication and analysis of an asymmetric cellulose acetate membrane for heat and moisture recovery. Journal of Membrane Science. 2011; 366(1-2):158-65.

[17] Zhang LZ. Progress on heat and moisture recovery with membranes: form fundamentals to engineering applications. Energy Conservation and Management. 2012; 63:173-95.

[18] Yoon JI, Phan TT, Moon CG, Bansal P. Numerical study on heat and mass transfer characteristic of plate absorber. Appl Therm Eng. 2005; 25:2219-35.

[19] Zhang LZ, WangYY, WangCL, XiangH. Synthesis and characterization of a PVA/LiCl blend membrane for air dehumidification. Journal of Membrane Science. 2008;308(12):198-206.

[20] Liu HM. Preparation and hydrophobic modification of polyvinylidene fluoride. Guangzhou: South China University of Technology; 2011.

[21] Moghaddam DG, Oghabi A, Ge GM, Besant RW, Simonson CJ. Numerical model of a small-scale liquid-to-air membrane energy exchanger: Parametric study of membrane 
680

681

682

683

684

685

686

687

688

689

690

691

692

693

694

695

696

697

698

699

700

701

702

703

704

705

706

707

708

709

710

711

712

713

714

715

716

resistance and air side convective heat transfer coefficient. Appl Therm Eng 2013; 61; 245-258.

[22] Hemingson HB, Simonson CJ, Besant RW. Steady-state performance of a run- around membrane energy exchanger (RAMEE) for a range of outdoor air conditions. Int J Heat Mass Transfer 2011; 54:1814-24.

[23] Hemingson $H$. The impacts of outdoor air conditions and non-uniform exchanger channels on a run-around membrane energy exchanger. (M. Sc. thesis). Saskatoon, Saskatchewan, Canada: Department of Mechanical Engineering, College of Engineering, University of Saskatchewan; 2010.

[24] Fan H. Modelling a run-around heat and moisture recovery system. (M.Sc. thesis). Saskatoon, Saskatchewan, Canada: Department of Mechanical Engineering, College of Engineering, University of Saskatchewan; 2005.

[25] Fan H, Simonson CJ, Besant RW, Shang W. Performance of a run-around system for HVAC heat and moisture transfer applications using cross-flow plate exchangers coupled with aqueous lithium bromide. HVAC \& R Res 2006; 12:313-36.

[26] Seyed-Ahmadi M. Modelling the transient behaviour of a run-around heat and moisture exchanger system. (M.Sc. thesis). Saskatoon, Saskatchewan, Canada: Department of Mechanical Engineering, College of Engineering, University of Saskatchewan; 2008.

[27] Seyed-Ahmadi M, Erb B, Simonson CJ, Besant RW. Transient behaviour of runaround heat and moisture exchanger system; part I: model formulation and verification. Int J Heat Mass Transf 2009; 52: 6000-11.

[28] Vali A, Simonson CJ, Besant RW, Mahmood G. Numerical model and effectiveness correlations for a run-around heat recovery system with combined counter and cross flow exchangers. Int J Heat Mass Transf. 2009; 52:5827-40.

[29] Vali A. Modelling a run-around heat and moisture exchanger using two counter/cross flow exchangers. (M.Sc.thesis). Saskatoon, Saskatchewan, Canada: Department of Mechanical Engineering, College of Engineering, University of Saskatchewan; 2009.

[30] Moghaddam DG, Le Poudre P, Besant RW, Simonson CJ. Steady-state performance of a small-scale liquid-to-air membrane energy exchanger for different heat and mass transfer directions, and liquid desiccant types and concentrations: experimental and numerical data. ASMEJ Heat Transfer 2013; 135:1-13.

[31] Huang SM, Zhang LZ, Tang K, Pei LX. Fluid and heat mass transfer in membrane parallel parallel-plates channels used for liquid desiccant air dehumidification. Int $\mathrm{J}$ Heat Mass Transfer 2012; 55:2571-80.

[32] Huang SM, Zhang LZ, Yang M. Conjugate heat and mass transfer in membrane parallel-plates ducts for liquid desiccant air dehumidification: effects of the developing entrances. J Membr Sci 2013; 437:82-9. 
[33] Huang SM, Zhong ZR, Yang ML. Conjugate heat and mass transfer in an internallycooled membrane-based liquid desiccant dehumidifier (IMLDD). J Membr Sci 2016; 508:73-83.

[34] Zhang LZ, Huang SM, Tang K, Pei LX. Conjugate heat and mass transfer in a hollow fiber membrane module for liquid desiccant air dehumidification: a free surface model approach. Int J Heat Mass Transf 2012; 55(13-14):3789-99.

[35] Zhang LZ, Huang SM, Pei LX. Conjugate heat and mass transfer in a cross-flow hollow fiber membrane contractor for liquid desiccant air dehumidification. Int J Heat Mass Transf 2013; 55(25-26):8061-72.

[36] Huang SM, Yang ML, Zhong WF, Xu YJ. Conjugate transport phenomena in a counter flow hollow fiber membrane tube bank: Effects of the fiber-to-fiber interactions. J Membr Sci 2013; 442:8-17.

[37] Huang SM, Yang ML. Heat and mass transfer enhancement in a cross-flow elliptical hollow fiber membrane contractor used for liquid desiccant air dehumidification. J Membr Sci 2014; 449:184-192.

[38] Huang SM, Qin FGF, Yang ML, Yang XX, Zhong WF. Heat and mass transfer deteriorations in an elliptical hollow fiber membrane tube bank for liquid desiccant air dehumidification. Appl Therm Eng 2013; 57:90-98.

[39] Abdel-Salam AH, Ge GM, and Simonson CJ. Performance analysis of a membrane liquid desiccant air-conditioning system, Energy Build 2013; 62:559-569.

[40] Moghaddam DG, LePoudre P, Ge GM, Besant RW, Simonson CJ. Small-scale singlepanel liquid-to-air membrane energy exchanger (LAMEE) test facility development, commissioning and evaluating the steady-state performance. Energy and Building 2013; 66:424-436.

[41] Melinder A. Thermophysical properties of aqueous solutions used as secondary working fluids, in: Energy Technology, KTH Energy and Environmental Technology, Stockholm, 2007.

[42] Taylor JR. An Introduction to Error Analysis: The Study of Uncertainties in Physical Measurements, second ed., University Science Books, Sausalito, CA, 1997.

[43] Zhang XM, Zhu T, An QS, Ren ZP, Mei FM. Heat Transfer, sixth ed., China Architecture \& Building Press, Beijing, 2014.

[44] Ghiaasiaan SM. Convective Heat and Mass Transfer, Cambridge University Press, Cambridge 2011.

[45] ANSI/ASHRAE STANDARD 84-2013, Method of test for air-to-air heat/energy exchangers, American society of heating, refrigerating, and air-conditioning engineers, Atlanta. 
[46] Simonson CJ, Besant RW. Energy wheel effectiveness: Part 1 - Development of dimensionless groups. Int J Heat Mass Transf 1999; 42:2161-70.

[47] Mander P (2012) How to convert relative humidity to absolute humidity available at <https://carnotcycle.wordpress.com/2012/08/04/ how-to-convert-relative-humidity-toabsolute-humidity/>.

[48] ASHRAE, 2013 ASHRAE Handbook Fundamentals. Atlantal 2013.

[49] Cisternas LA and Lam EJ. An analytic correlation for the vapour pressure of aqueous and non-aqueous solutions of single and mixed electrolytes. Part II. Application and extension. Fluid Phase Equilib 1991; 62:11-27.

[50] Erb B. Run-around membrane energy exchanger performance and operational control strategies, M.Sc. Thesis, University of Saskatchewan, Saskatoon, SK, 2009.

[51] Namvar R, Pyra D, Ge GM, Simonson CJ. Transient characteristics of a liquid-to-air membrane energy exchanger (LAMEE) experimental data with correlations. Int J Heat Mass Transf, 2012; 55:6682-6694.

[52] Niu JL and Zhang LZ. Membrane-based enthalpy exchanger: material considerations and clarification of misture resistance. J Membr Sci 2001; 189(2): 179-191.

[53] Abdel-Salam AH, Ge GM, and Simonson CJ. Performance analysis of a membrane liquid desiccant air-conditioning system, Energy Build 2013; 62:559-569.

[54] Mahmud K, Mahmood GI, Simonson CJ and Besant RW. Performance testing of a counter-cross-flow run-around membrane energy exchanger (RAMEE) system for HVAC applications, Energy Build 2010; 42(7):1139-1147. 